\title{
Remote sensing of ice crystal asymmetry parameter using multi-directional polarization measurements - Part 2: Application to the Research Scanning Polarimeter
}

\author{
B. van Diedenhoven ${ }^{1,2}$, B. Cairns ${ }^{2}$, A. M. Fridlind ${ }^{2}$, A. S. Ackerman ${ }^{2}$, and T. J. Garrett ${ }^{3}$ \\ ${ }^{1}$ Columbia University, Center for Climate System Research, New York, NY, USA \\ ${ }^{2}$ NASA Goddard Institute for Space Studies, New York, NY, USA \\ ${ }^{3}$ Department of Atmospheric Sciences, University of Utah, Salt Lake City, Utah, USA \\ Correspondence to: B. van Diedenhoven (bastiaan.vandiedenhoven@nasa.gov)
}

Received: 15 October 2012 - Published in Atmos. Chem. Phys. Discuss.: 14 December 2012 Revised: 6 March 2013 - Accepted: 7 March 2013 - Published: 18 March 2013

\begin{abstract}
A new method to retrieve ice cloud asymmetry parameters from multi-directional polarized reflectance measurements is applied to measurements of the airborne Research Scanning Polarimeter (RSP) obtained during the CRYSTAL-FACE campaign in 2002. The method assumes individual hexagonal ice columns and plates serve as proxies for more complex shapes and aggregates. The closest fit is searched in a look-up table of simulated polarized reflectances computed for cloud layers that contain individual, randomly oriented hexagonal columns and plates with a virtually continuous selection of aspect ratios and distortion. The asymmetry parameter, aspect ratio and distortion of the hexagonal particle that leads to the best fit with the measurements are considered the retrieved values. Two cases of thick convective clouds and two cases of thinner anvil cloud layers are analyzed. Median asymmetry parameters retrieved by the RSP range from 0.76 to 0.78 , and are generally smaller than those currently assumed in most climate models and satellite retrievals. In all cases the measurements indicate roughened or distorted ice crystals, which is consistent with previous findings. Retrieved aspect ratios in three of the cases range from 0.9 to 1.6 , indicating compact particles dominate the cloud-top shortwave radiation. Retrievals for the remaining case indicate plate-like ice crystals with aspect ratios around 0.3 . The RSP retrievals are qualitatively consistent with the CPI images obtained in the same cloud layers. Retrieved asymmetry parameters are compared to those determined in situ by the Cloud Integrating Nephelometer (CIN). For two cases, the median values of asymmetry parameter
\end{abstract}

retrieved by CIN and RSP agree within 0.01 , while for the two other cases RSP asymmetry parameters are about 0.03 0.05 greater than those obtained by the CIN. Part of this bias might be explained by vertical variation of the asymmetry parameter or ice shattering on the CIN probe, or both.

\section{Introduction}

The ice crystal asymmetry parameter is one of the fundamental radiative properties of ice clouds for climate model projections (Coakley and Chylek, 1975). However, current knowledge of the global variation of ice crystal asymmetry parameter and its possible correlation with, for example, ice cloud type, cloud-top temperature and ice effective radius is insufficient. Vogelmann and Ackerman (1995) estimated that asymmetry parameters must be known to within 2-5\% (or about 0.02 to 0.04 in absolute terms) to constrain computed shortwave fluxes to within about $5 \%$. However, estimates of asymmetry parameter using flux measurements and radiative transfer calculations range from about 0.7 to about 0.85 (e.g. Platt et al., 1980; Stephens et al., 1990; Francis et al., 1994; Mitchell et al., 1996). In situ measurements made with the Cloud Integrating Nephelometer (CIN) and the Polar Nephelometer (e.g. Gayet et al., 1997, 2006, 2012; Gerber et al., 2000; Auriol et al., 2001; Garrett et al., 2001, 2003, 2005; Baran et al., 2005, see Garrett (2008) for an overview), generally yield values close to 0.75 with little dependence on location and temperature. However, these asymmetry parameters 
observed in situ provide poor spatial coverage and do not always represent values at the top of the clouds relevant for solar reflectances. Moreover, such small asymmetry parameters around 0.75 are seemingly inconsistent with the occasional sightings of halos within ice clouds from surface observations (Sassen et al., 2003) that imply pristine ice crystals, which generally have high asymmetry parameters (e.g. Baum et al., 2011; Yang et al., 2013).

In Part 1 of the paper (van Diedenhoven et al., 2012a), we presented a new method to remotely sense the ice crystal asymmetry parameter using multi-directional polarized reflectance measurements. Additionally, the method provides estimates for the microscale surface roughness or distortion of the ice crystals and the effective aspect ratios (AR) of their components. In the current paper we apply this technique to measurements made by the airborne Research Scanning Polarimeter (RSP) obtained during the Cirrus Regional Study of Tropical Anvils and Cirrus Layers - Florida Area Cirrus Experiment (CRYSTAL-FACE) campaign in July 2002. Furthermore, cloud optical thicknesses and cloud-top heights are simultaneously derived from RSP measurements using established techniques. The results are evaluated using nearcollocated measurements of the CIN, the Cloud Particle Imager (CPI), the MODIS Airborne Simulator (MAS) and cloud radar.

\section{Retrieval procedures and data processing}

The primary measurements used in this work were obtained with the Research Scanning Polarimeter (RSP) instrument (Cairns et al., 1999, 2003), an airborne version of the Aerosol Polarimetry Sensor satellite instrument (Mishchenko et al., 2007) that was lost during the failed launch of the Glory mission in March 2011. The RSP provides simultaneous measurements of total and polarized reflectances in 9 bands from the visible to the shortwave infrared. During CRYSTALFACE, one of the two available RSP instruments was mounted on the Proteus high-altitude aircraft built by Scaled Composites, LLC. The RSP scans along track, providing measurements of each pixel at 152 different viewing angles at $0.8^{\circ}$ intervals. During CRYSTAL-FACE the instrument was mounted on the aircraft at an angle of approximately $14.5^{\circ}$, leading to viewing angles ranging from $+45^{\circ}$ to $-75^{\circ}$. The instantaneous field-of-view of the RSP is $14 \mathrm{mrad}$, leading to typical pixel sizes of about $40-150 \mathrm{~m}$ at nadir for the aircraft altitudes and cloud-top heights occurring during CRYSTAL-FACE. The instrument is primarily designed to provide exceptionally accurate information about aerosols (e.g. Chowdhary et al., 2002; Knobelspiesse et al., 2012) but has been shown to provide unique information about liquid clouds as well (Knobelspiesse et al., 2011; Alexandrov et al., 2012). To date, little RSP data over ice clouds have been analyzed (e.g. Ottaviani et al., 2012), and the CRYSTAL-FACE dataset currently provides the only substantial collection of RSP measurements over ice clouds.

\subsection{Asymmetry parameter and optical thickness retrieval}

Asymmetry parameters are retrieved from the multi-direction polarized reflectance measurements using the method described in detail in Part 1. The method is based on previous findings that (a) complex aggregates of hexagonal crystals generally have scattering phase matrices resembling those of their components (e.g. Fu, 2007; Um and McFarquhar, 2007, 2009), and (b) scattering phase matrices systematically vary with aspect ratios of crystals and their degree of distortion or microscale surface roughness (e.g. Fu, 2007; Yang and Fu, 2009). Individual hexagonal ice columns and plates are assumed to serve as proxies for more complex shapes and aggregates. As shown in Part 1, smooth, undistorted hexagonal columns produce strong features in the degree of polarization functions at the scattering angles usually observed by multidirectional polarimeters $\left(\gtrsim 100^{\circ}\right)$. Similar, but sharper structures are generally obtained for plates (e.g. Takano and Liou, 1989). Such features are systematically diminished with increasing distortion or microscale surface roughness (Part 1; Macke et al., 1996; Yang et al., 2008). Furthermore, as shown in Part 1, the polarization from hexagonal ice crystals generally increases when their aspect ratio increasingly deviates from unity, especially at scattering angles smaller than about $140^{\circ}$. Thus, a best fit to multi-directional polarization measurements at $864 \mathrm{~nm}$ is sought within a look-up table (LUT) calculated by assuming individual hexagonal particles with varying aspect ratios ( $\mathrm{AR}=0.02-50$ ) and distortion parameters $(\delta=0-0.7$; see Macke et al. (1996) and below for a definition of $\delta$ ), which have asymmetry parameters ranging from 0.71 to 0.94 . The asymmetry parameter of the corresponding column or plate is considered to be representative (i.e. the retrieved value) of the asymmetry parameter of the ice crystal ensemble at the top of the observed cloud. For clouds with optical thickness less than 5, the cloud optical thickness must be retrieved simultaneously with the asymmetry parameter, while for optically thicker clouds the asymmetry parameter retrieval is independent of cloud optical thickness.

The LUT is calculated using the doubling-adding method (Hansen and Travis, 1974; de Haan et al., 1987) assuming a single uniform plane-parallel cloud layer. The ice crystal optical properties are calculated using the standard geometric optics code developed by Macke et al. (1996). This ray tracing code takes distortion of ice crystals into account in a statistical manner by perturbing, for each interaction with a ray, the normal of the crystal surface from its nominal orientation by an angle varied randomly with uniform distribution between $0^{\circ}$ and $\delta \times 90^{\circ}$, where $\delta$ is referred to as the distortion parameter. Thus, this approach represents the stochastic large-scale distortion of a collection of ice crystals. However, Yang et al. (2008) found that this approach is also an 
efficient, yet accurate treatment of microscale surface roughness. For a large collection of ice crystals, microscale surface roughness and large-scale particle distortion both lead to a similar randomization of the angles between crystal facets, which in turn leads to the diminishing of features in the scattering phase matrix. Increasing the number of impurities within ice crystals also has a similar effect (Hess et al., 1998). Thus, we consider the distortion used here a proxy of randomization of the angles between crystal facets possibly caused by any of these effects. Furthermore, our approach is based on the common assumption that ice crystals consist of fundamental hexagonal structures that can be either smooth or distorted. Some evidence exists that, under some conditions, small ice crystals can form or evolve into other shapes, such as spheroids (e.g., Mishchenko and Sassen, 1998; Nelson, 1998; Lawson et al., 2010; Gayet et al., 2012). In future work, application of our approach to clouds consisting of particles fundamentally different from hexagonal prisms should be evaluated.

The retrieval technique was evaluated in Part 1 using simulated measurements based on state-of-the-art optical properties of smooth, moderately roughened and severely roughened solid plates, solid and hollow columns, solid and hollow bullet rosettes, droxtals, aggregates of columns and aggregates of plates, as well as several mixtures of these habits (Baum et al., 2005a, 2011; Yang et al., 2013). The evaluation showed that the ice crystal asymmetry parameters are generally retrieved to within $5 \%$, or about 0.04 in absolute terms, largely independent of calibration errors, range and sampling density of scattering angles and random noise in the measurements. Moreover, plate-like, column-like, smooth and rough particles were found to be generally correctly identified. The area-weighted mean aspect ratio of the particles (or their components) (cf. Fu, 2007) is retrieved by this method. In the case of mixtures of plates and columns, the technique is expected to yield aspect ratios approximately equal to the area-weighted mean of AR for plates plus 1/AR for columns (or 1/AR for plates plus AR for columns). For example, for a cloud in which plates with $\mathrm{AR}=0.1$ and columns with $\mathrm{AR}=2$ each contribute half of the total cross-sectional area, we expect the retrieved aspect ratio would be either close to $(0.1+1 / 2) / 2=0.3$ or $(1 / 0.1+2) / 2=6$. However, this should be verified in future work.

For the inference of ice crystal asymmetry parameter, the relative root-mean-squared difference (RRMSD, Eq. (5) in Part 1) between polarization measurements at the considered angles and the corresponding simulated values from our look-up table is determined for each combination of aspect ratio and distortion, and the combination leading to the lowest RRMSD corresponds to the retrieved asymmetry parameter. In this study, for each analyzed CRYSTAL-FACE flight leg, a separate LUT is calculated assuming the mean solar zenith and relative azimuth angle of the flight leg. To determine the RRMSD, the measurements are interpolated to the scattering angles at which the LUT is determined. This is done, rather than interpolating the entire LUT to the scattering angles of each measurement, to reduce computational effort. Note, however, that maximum differences in scattering angle grid of the measurements and the LUT are only about $0.4^{\circ}$.

Based on the analysis presented in Part 1, asymmetry parameters are only retrieved if measurements are available for scattering angles between $120^{\circ}$ and $150^{\circ}$. Measurements with polarized reflectances lower than 0.002 or scattering angles greater than $165^{\circ}$ (at which polarized reflectance over ice clouds are usually near zero) are excluded to avoid overwhelming influence of instrument noise as well as geometry and calibration uncertainties. Since the RSP noise and calibration uncertainties in polarized reflectances above clouds are expected to be well below 0.002, independent of measurement geometry (Knobelspiesse et al., 2012), this filtering can be considered conservative. Furthermore, measurements for which the estimated degree of polarization from ocean sunglint exceeds $0.5 \%$ are excluded. For this, sunglint is simulated using the rough ocean surface approximation by Cox and Munk $(1954,1956)$ with a windspeed of $4 \mathrm{~ms}^{-1}$, and the extinction of the sunglint through the cloud layer is calculated using Beer's law. Note that this estimate of contamination of sunglint is approximate and that the threshold of $0.5 \%$ is a conservative one based on visual inspection of the polarized reflectances measured over clouds at sunglint geometries.

Since the asymmetry parameter retrieval is independent of cloud optical thickness for clouds with optical thickness greater than about 5, asymmetry parameters are retrieved for these pixels using a LUT with an arbitrary large optical thickness $\left(\tau_{\mathrm{c}}=50\right)$, as described in Part 1. Pixels with a cloud optical thickness larger than 5 are identified by the requirement that the measured total reflectance in the $864 \mathrm{~nm}$ channel near nadir is larger than the smallest value appearing in the corresponding LUT for a cloud optical thickness of 5. Note that this threshold technique is conservative since the reflectance of a cloud with optical thickness of 5 decreases substantially with increasing asymmetry parameter.

For optically thinner clouds, the apparent optical thickness yielding a total reflectance that matches measurements also depends on the assumed ice asymmetry parameter (Zhang et al., 2009), and hence it needs to be determined for all aspect ratio and distortion combinations in the LUT, as discussed in Part 1. For this, the LUT contains calculated reflectances for cloud optical thickness $\tau_{\mathrm{c}}$ varying by 0.1 in the range $\tau_{\mathrm{c}}=0.1-1$ and varying by 1 in the range $\tau_{\mathrm{c}}=1-10$. For every aspect ratio and distortion value, the apparent optical thickness is determined by minimizing the differences between measured and simulated total reflectances at $864 \mathrm{~nm}$ at the viewing angle closest to nadir. The asymmetry parameter is then determined from the polarized reflectances, as discussed above, and the optical thickness associated with that retrieval is considered to be the retrieved optical thickness. 
For completeness, the optical thickness of clouds that were identified as optically thick $\left(\tau_{\mathrm{c}}>5\right)$ are retrieved after the asymmetry parameter is determined. For this, a separate LUT is calculated containing total reflectances for clouds with optical thickness values varying with steps of 1 for $\tau_{\mathrm{c}}=10$ 20 and with steps of 2 for optically thicker clouds up to $\tau_{\mathrm{c}}=100$. To reduce the size of this LUT, the optical properties of all hexagonal plates and columns in the original LUT are averaged in 0.02 wide asymmetry parameter bins between 0.7 and 0.86 . The nadir reflectances corresponding to the asymmetry parameter that are closest to the retrieved value are then used to determine the cloud optical thickness. If the asymmetry parameter is not retrieved for a given pixel owing to the data selection criteria, the optical thickness is retrieved using the LUT corresponding to an asymmetry parameter of 0.78 .

In order to assess to which optical depth within the cloud top the retrieved asymmetry parameters correspond, Fig. 1 shows polarized reflectances at a scattering angle of $120^{\circ}$ for cloud layers with increasing optical thickness relative to the polarized reflectances of optically thick clouds $\left(\tau_{\mathrm{c}}=50\right)$. This figure shows that for clouds with an optical thickness larger than about 5 the polarized reflectance is nearly saturated, as discussed above and in Part 1. Furthermore, twothirds of the maximum polarized reflectance is reached at a cloud optical thickness of about 0.8 to 2 , depending on the asymmetry parameter. From this we estimate that the polarized reflectances used to retrieve asymmetry parameters are dominated by the first one or two units of optical depth in the cloud layer (cf. Platnick, 2000). Similar results are obtained for other scattering angles. In future work, vertical weighting functions of the polarized radiance field could be calculated and evaluated against realistic cloud model simulations (cf. Zhang et al., 2010; Alexandrov et al., 2012).

\subsection{Cloud-top height retrievals}

Cloud-top height estimates are needed to process the level1 RSP observations into data suitable for the asymmetry parameter retrieval, as explained in Sect. 2.3. Cloud-top height is estimated from polarized reflectances based on the method described by Buriez et al. (1997), which is operationally applied to measurements of the Polarization and Directionality of the Earth's Reflectances (POLDER) instrument. The molecular Rayleigh scattering signature in polarized reflectances is used to estimate the column of air between the cloud and the aircraft, from which the cloud height can be derived. The method relies on the fact that the signal of Rayleigh scattering in the polarized reflectance signal is strong at scattering angles in the range $60-120^{\circ}$ at short wavelengths, but negligible at longer wavelengths, while the contributions of clouds to the polarized reflectance are comparable at all wavelengths in the visible to near-infrared.

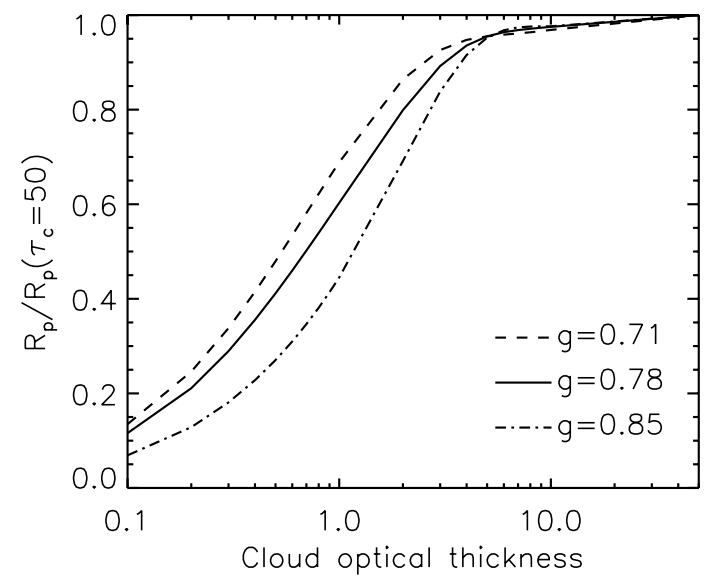

Fig. 1. Polarized reflectance $R_{\mathrm{p}}$ as a function of cloud optical thickness $\tau_{\mathrm{c}}$ relative to its value at $\tau_{\mathrm{c}}=50$. Different linestyles indicate calculations made assuming different asymmetry parameters as indicated. Solar zenith, viewing and relative azimuth angles are $13^{\circ}$, $52^{\circ}$ and $55^{\circ}$, respectively, leading to a scattering angle of $120^{\circ}$.

The contribution of Rayleigh scattering to the polarized reflectance $R_{\mathrm{p}, \mathrm{r}}$ at a wavelength $\lambda$ and scattering angle $\gamma$ is approximated by the single scattering approximation via

$R_{\mathrm{p}, \mathrm{r}}(\lambda)=\frac{3}{16} \frac{1-\cos ^{2} \gamma}{\mu_{0} \mu} \Delta \tau_{\mathrm{r}}$

where $\mu_{0}$ and $\mu$ are the cosine of the solar zenith and viewing angles, respectively, and $\Delta \tau_{\mathrm{r}}(\lambda)$ is the Rayleigh optical thickness of the air column between the aircraft and the cloud (or other lower boundary). $R_{\mathrm{p}, \mathrm{r}}$ at $410 \mathrm{~nm}$ can be estimated by correcting the polarized radiances measured by the $410 \mathrm{~nm}$ channel of RSP using those at $864 \mathrm{~nm}$, where Rayleigh scattering is negligible:

$R_{\mathrm{p}, \mathrm{r}}(\lambda=410 \mathrm{~nm}) \approx \frac{\pi \sqrt{\left(Q_{410}^{2}+U_{410}^{2}\right)-\left(Q_{864}^{2}+U_{864}^{2}\right)}}{\mu_{0} F_{\odot}}$,

where $F_{\odot}$ is the solar irradiance, and $Q$ and $U$ are the second and third Stokes parameters, respectively (van de Hulst, 1957). In turn, $\Delta \tau_{\mathrm{r}}$ at $410 \mathrm{~nm}$ can be estimated using Eqs. (1) and (2).

The Rayleigh optical thickness of the total column of air from top of atmosphere to sea level, $\tau_{\lambda, 0}$, can be estimated by (Hansen and Travis, 1974; Bodhaine et al., 1999)

$\tau_{\mathrm{r}, 0}(\lambda)=0.008569 \lambda^{-4} \times\left(1+0.0113 \lambda^{-2}+0.00013 \lambda^{-4}\right)$.

Since the Rayleigh optical depth is proportional to pressure, $\Delta \tau_{\mathrm{r}}$ relates to cloud-top and aircraft heights, $z_{\text {cloud }}$ and $z_{\text {aircraft }}$, respectively, through

$\Delta \tau_{\mathrm{r}}=\tau_{\mathrm{r}, 0} \times e^{-z_{\text {cloud }} / H} \times\left(1-e^{-z_{\text {aircraft }} / H}\right)$, 
where $H$ is the scale height of atmospheric pressure given by the hydrostatic approximation, which is approximately $7.4 \mathrm{~km}$ at mid-troposphere. Thus, by inverting Eq. (4), $z_{\text {cloud }}$ can be derived from $\Delta \tau_{\mathrm{r}}$ estimated from the RSP measurements and Eqs. (1) and (2). The flight altitude of the Proteus during CRYSTAL-FACE is available in the aircraft navigation files and generally was about $17 \mathrm{~km}$ for the analyzed legs.

Following Buriez et al. (1997), the cloud-top height is only estimated for measurements with scattering angles between $60-120^{\circ}$. Since several measurements are generally available in this scattering angle range for a given RSP field-of-view, the median of the derived cloud-top heights is used here, while the differences between maximum and minimum values are used as an indication of uncertainty.

This simple cloud-top height estimate assumes opaque cloud layers, ignores multiple Rayleigh scattering, and is therefore expected to underestimate the cloud-top height for optically thin clouds $(\tau \lesssim 3$ ) (Buriez et al., 1997), as also shown later. Cloud transmission and multiple Rayleigh scattering may be corrected for using look-up tables (cf. Buriez et al., 1997). Since we are mainly focusing here on relatively optically thick clouds for which polarized reflectances are nearly saturated (see Fig. 1), such corrections are assumed to be minimal and therefore are not applied here. Development of a more versatile cloud-top height retrieval algorithm for RSP is planned for future work.

\subsection{RSP Level-1 data processing}

At a given location of the aircraft, the RSP acquires measurements at 152 different viewing angles, which all target a different location on the cloud deck. Before cloud physical properties can be determined from the data, the actual RSP scans must be aggregated to obtain multi-directional observations for a certain location (pixel) at cloud top (Alexandrov et al., 2012). For this aggregation, knowledge of the cloud height, the angle at which the instrument is mounted on the aircraft, and the aircraft's position, altitude and attitude (pitch, roll, crab angles) are crucial. Unfortunately, Proteus attitude information was not recorded during CRYSTALFACE. For the relatively straight flight legs analyzed here, we assume the roll angle to be negligible and the aircraft to be oriented parallel to the flight direction. The pitch of the aircraft and the instrument mounting angle together determine the angular difference between the nadir direction in the instrument's reference plane and the actual nadir direction, here dubbed the effective pitch. The effective pitch can be estimated by (1) using distinct features in the polarized reflectance data at well-determined scattering angles, such as those from the liquid cloud "rainbow", ocean sunglint and Rayleigh scattering; or (2) determining the cloud-top height using the technique described in Sect. 2.2 and validating it against auxiliary information. Here, we mainly use the latter technique using collocated cloud-top height information from cloud radar, MODIS airborne simulator (MAS) and in situ aircraft measurements. As demonstrated later, an effective pitch of $12^{\circ}$ yields a cloud-top height from RSP that generally matches the auxiliary cloud-top height information within about $1 \mathrm{~km}$ for the considered flight legs. In addition, the effective pitch of $12^{\circ}$ also leads to ocean sunglint features that are at the expected scattering angles. Furthermore, rainbow features over liquid clouds appear around a scattering angle of $140^{\circ}$, as expected, although such features are present only in flight legs not analyzed here, since we focus on ice clouds. Given that the mounting angle of the RSP was determined to be approximately $14.5^{\circ}$, an effective pitch of $12^{\circ}$ indicates that the aircraft attack angle was about $2.5^{\circ}$ on average. The cloud-top height retrieved with the technique described in Sect. 2.2 increases about $0.3 \mathrm{~km}$ for each degree decrease in effective pitch. Hence, the uncertainty in effective pitch is estimated to be about $3^{\circ}$. In Sect. 3 , we discuss the uncertainties in the retrieved asymmetry parameters associated with this uncertainty in aircraft geometry.

The Proteus aircraft was not particularly stable during the CRYSTAL-FACE flights. Oscillations in the aircraft attitude are evident in the data as wave patterns traversing over scattering angles in the consecutively measured polarized reflectances plotted as a function of time. The magnitude and frequency of these patterns varies between flight legs. Aircraft attitude variations are relatively small for the parts of the flight legs selected for this paper. The influence of such patterns on the retrieval products is difficult to quantify, but no obvious artifacts associated with attitude variations are apparent in the retrieved parameters.

Additional uncertainties in the angular aggregation are caused by cloud-top heights that vary substantially over the the flight leg, such as for a cloud edge. Such effects of cloud structure and inhomogeneity lead to an increased difference between cloud-top heights retrieved from measurements at different scattering angles using the method described in Sect. 2.2. Currently, pixels for which the difference between minimum and maximum retrieved cloud-top heights exceed $3 \mathrm{~km}$ are excluded. For the four cases studied here, this filter excludes only some pixels at cloud edges, but few pixels remain if a smaller threshold is used.

\subsection{Cloud integrating nephelometer data}

We compare the asymmetry parameters retrieved from RSP data with in situ measurements from the airborne CIN (Gerber et al., 2000; Garrett et al., 2005), which determines the extinction coefficient and asymmetry parameter in clouds at visible wavelengths from the measured integrated intensity in forward- and back-scattering regimes. The measurements are theoretically corrected for the undersampling of the forward scattering peak (Gerber et al., 2000). The approximate accuracy of the derived asymmetry parameter is 0.02 (Garrett et al., 2003). A detailed description and overview of 
measurements of the CIN and similar probes in several cloud types is given by Garrett (2008).

During CRYSTAL-FACE, CIN instruments were mounted on the WB-57 and Citation aircraft. However, the CIN on the WB-57 had one faulty channel, which inhibited the retrieval of the asymmetry parameter from its measurements. Thus, only CIN data from the Citation are used in this paper. Asymmetry parameters are derived from the measurements as described by Gerber et al. (2000) and Garrett et al. (2003). Only data with a signal-to-noise ratio higher than 15 in the backscattering channel are used to minimize uncertainties owing to random shot noise and ambient light.

As confirmed recently by Korolev et al. (2011), most in situ probes measuring in ice clouds can be subject to issues associated with shattering of large ice crystals on the probes or aircraft. Evidence of shattering in the data of the Cloud Particle Imager probe on the Citation during CRYSTALFACE has been seen (C. Schmitt, personal communication, 2011), although the severity and effect of shattering is unique to each instrument design (Korolev et al., 2011). For example, the CIN has a much larger aperture than the CPI. However, Garrett (2007) argued, based on intercomparisons among in situ probes and with remote sensing retrievals (e.g. Noel et al., 2007), that shattering effects on the CIN measurements during CRYSTAL-FACE were likely to have been limited. Where shattering occurs, it would expose more surface area, leading to positively biased extinction measurements, as argued by Heymsfield et al. (2006). The potential effect of shattering on asymmetry parameters measured by the CIN is difficult to estimate. In the hypothetical case of large particles composed of components with aspect ratios substantially deviating from unity that shatter into numerous small particles with aspect ratios close to unity, the retrieved asymmetry parameter would probably be biased low (see Fig. 1 in Part 1) with positive biases owing to ice shattering seeming less likely. However, if aggregates merely break up into their components, the effect on asymmetry parameters measured in situ is likely to be minimal, since aggregates of crystals have similar asymmetry parameters as their components (Part 1; Um and McFarquhar, 2007, 2009; Baran, 2009).

\subsection{Other data}

In addition to the RSP and CIN data, we use data from the Cloud Particle Imager probe (CPI, Lawson et al., 2001) mounted on the WB-57, the MODIS Airborne Simulator (MAS, King et al., 2004) mounted on the ER-2, and the 94-GHz Cloud Radar System (CRS, Li et al., 2004) on the ER-2. CPI data and auxiliary aircraft navigation data were downloaded from NASA's Earth Science Project Office (ESPO) data archive. MAS level-1 data was downloaded from NASA's MAS website. Because substantial biases on the measurements of the visible and shortwave infrared channels of MAS were recently identified (T. Arnold, personal communication, 2012), we do not use MAS data in this wavelength range or the MAS level-2 products derived from them, such as effective radius and cloud optical thickness. CRS data was downloaded from NASA's High-Altitude Radar website. Flight track images were obtained from the NASA Langley CRYSTAL-FACE Satellite Page.

\section{Results}

Results from four Proteus flight segments shown in Fig. 2 are presented here: two flight legs that have collocated CRS, MAS and CIN data (29 and 11 July); and two flight legs for which nearby vertical transects of CIN measurements are available (7 July and 21 July). Thick convective clouds were sampled on 29 and 7 July, while thinner anvil cloud layers were sampled on 11 and 21 July. In all cases the anvils sampled were roughly $1.5-2 \mathrm{~h}$ aged and active cells remained in some contiguous region of the sampled cloud.

\subsection{July 2002}

On 29 July 2002, a large storm developed at around 17:0018:00 UTC on Florida's west coast (Fig. 2a) and it was sampled by all aircraft involved in the CRYSTAL-FACE campaign in the next 2-3 h (e.g. Li et al., 2004; Noel et al., 2004; Chepfer et al., 2005; Lopez et al., 2006). Here we analyzed measurements obtained at roughly 20:30 UTC in outflow aged by roughly $2 \mathrm{~h}$. The mean solar zenith and relative azimuth angles for RSP data in this case are $41^{\circ}$ and $10^{\circ}$, respectively.

Figure 3 shows cloud-top heights, optical thickness, asymmetry parameter, distortion and aspect ratio retrieved from RSP measurements as a function of time, along with CRS reflectivity profiles, MAS $11 \mu \mathrm{m}$ brightness temperature cloudtop heights collocated with the CRS track, and extinction and asymmetry parameters retrieved by the CIN. The Proteus (RSP) and ER-2 (CRS, MAS) aircrafts were well collocated for these legs and CRS and MAS data are shifted and stretched according to the aircraft proximity files available in NASA's ESPO repository. The CIN data were acquired about 30 min earlier and the Citation aircraft sampled the storm at a slightly different attack angle. The CIN data are shifted and stretched in time according to the flight tracks and to match features in the retrieved extinction to those in the CRS radar reflectivity.

The cloud radar shows cloud-top heights around 12$14 \mathrm{~km}$, with slightly lower cloud-top heights in the trailing anvil than in the leading anvil (Fig. 3a), as may be typical (Cetrone and Houze, 2011). An apparently overshooting top occurs around $73.75 \mathrm{ks}$ UTC Proteus time (i.e. time corresponding to the RSP data). High reflectivities occur around $73.5 \mathrm{ks}$ UTC towards the leading part of the storm. A prominent rain band is seen at 73.6-73.8 ks UTC below about $4 \mathrm{~km}$ where the radar signal is severely attenuated in spots (Li et al., 2004). The radar profile generally resembles 

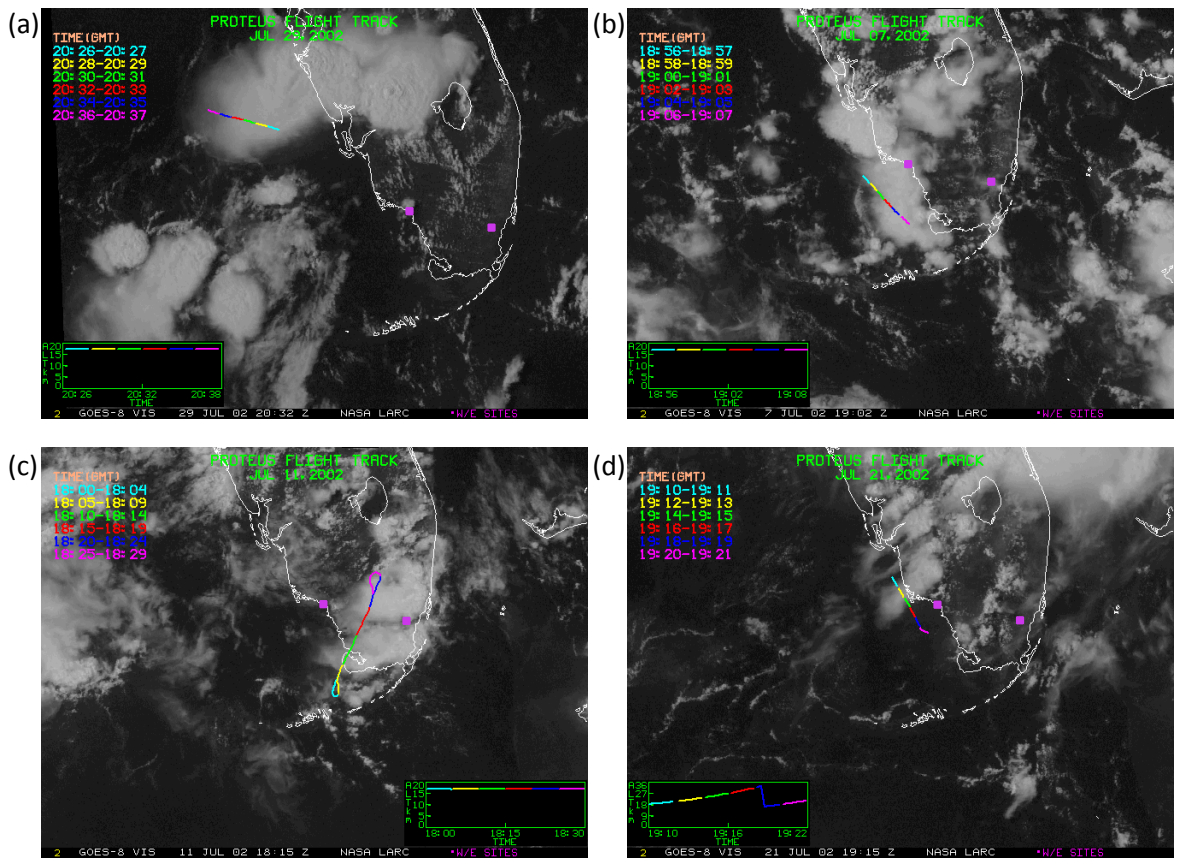

Fig. 2. GOES-8 visible images with Proteus flight track for (a) 29 July; (b) 7 July; (c) 11 July; and (d) 21 July. The magenta dots mark the western and eastern ground sites. On 11 July, the most northern storm in the flight track is investigated in Fig. 10. Plotted Proteus altitude information for 21 July is not correct. Figures courtesy of Patrick Minnis and Louis Nguyen, NASA Langley Research Center.

the classic representation of a deep convective system, as presented by Houze (1981). For the bulk of the storm RSP retrieves cloud-top heights of $12-15 \mathrm{~km}$. The differences between minimum and maximum RSP cloud-top heights are less than $100 \mathrm{~m}$, indicating the Proteus was stable during the flight leg, the cloud top is relatively homogeneous, and the estimated effective pitch is appropriate (see Sect. 2.2). At the overshooting top the RSP retrieved cloud top is about $0.5 \mathrm{~km}$ higher than the radar cloud top, on average, and more variable. In the trailing anvil the estimated cloud heights are substantially lower than the radar cloud top, presumably owing to the erroneous assumption of opaque clouds in the cloudtop height retrieval method, as described in Sect. 2.2. Note that the Proteus was turning over the leading anvil and no RSP data are available there. RSP cloud-top heights compare well with MAS $11 \mu \mathrm{m}$ brightness temperature cloudtop heights, especially near and over the trailing and leading anvils. Interestingly, the underestimation of cloud top retrieved by MAS is very similar to that seen by RSP, which might be expected since the retrieval of cloud top from the $11 \mu \mathrm{m}$ brightness temperature also assumes opaque clouds (Minnis et al., 2008). However, the MAS cloud-top height is only minimally higher in the region of the overshooting top detected by the radar and RSP. Figure $3 \mathrm{a}$ also shows that the CIN mounted on the Citation aircraft was sampling the cloud at about $12 \mathrm{~km}$, just below cloud top.

Figure $3 b$ shows the optical thickness retrieved from RSP measurements, which is about 40-100 at the core of the sys- tem and strongly decreases in the trailing anvil. Extinction values retrieved by the CIN reach up to $200 \mathrm{~km}^{-1}$.

Asymmetry parameters retrieved by the RSP are shown in Fig. $3 \mathrm{c}$ and generally range from about 0.76 to 0.8 with a median of 0.78 . The smallest asymmetry parameters are generally found at the location with greatest optical thickness and radar reflectivity in the cloud top (around $73.5 \mathrm{ks}$ UTC). No retrievals are performed in the optically thin part of the leading anvil because of a substantial influence of ocean sunglint. The retrieved asymmetry parameters correspond to hexagonal columns with a median aspect ratio of 1.6 (Fig. 3e) and a median distortion of 0.45 (Fig. 3d). Polarized reflectances used to retrieve asymmetry parameters are generally weighted towards the first few optical depths in a cloud (see Sect. 2.1 and Fig. 1). Since $11 \mu \mathrm{m}$ brightness temperatures generally represent the cloud temperature over the first optical depth (Minnis et al., 2008), the asymmetry parameter retrieved by the RSP is likely representative of a level close to the MAS cloud-top height shown in Fig. 3a. As discussed in Sect. 2.3, the aircraft pitch angle was not recorded during CRYSTAL-FACE and is estimated with an uncertainty of about $3^{\circ}$. Increasing or decreasing the effective pitch angle with $3^{\circ}$ leads to a mean increase or decrease of the retrieved asymmetry parameter of 0.008 , which is a small effect compared to the overall accuracy of the retrieval method, which is estimated to be 0.04 (Part 1).

Figure $3 \mathrm{c}$ also shows asymmetry parameters retrieved by the CIN, which are substantially lower and range from 0.7 


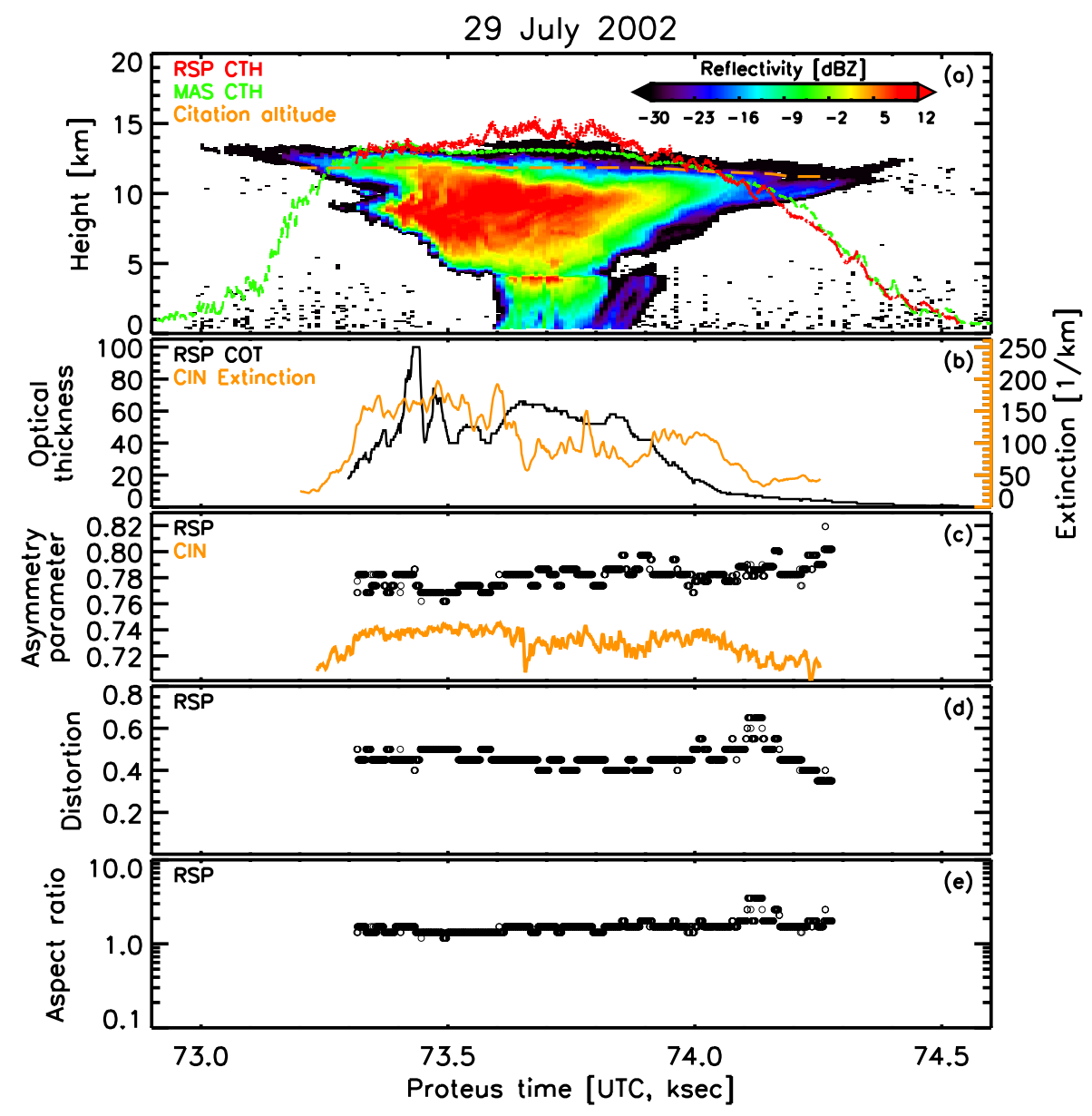

Fig. 3. RSP, CRS, MAS and CIN data for 29 July 2002 as a function of time corresponding to the RSP data on the Proteus aircraft. CRS, MAS and CIN data are shifted and stretched/squeezed in time to best collocate with the RSP data. (a) Cloud radar reflectivity (color contours); RSP retrieved cloud-top height (red) with minimum and maximum retrieved heights in dotted lines; cloud-top height derived from MAS $11 \mu \mathrm{m}$ brightness temperature (green) and altitude of Citation aircraft carrying CIN (orange dashed). (b) Cloud optical thickness (COT) retrieved by RSP (black, left axis) and extinction derived from CIN (orange, right axis). (c) Asymmetry parameter retrieved from RSP (black) and CIN (orange). (d) Distortion parameter from RSP. (e) Aspect ratio from RSP.

to 0.74 with a median of 0.73 . While the difference between the median values derived from RSP and CIN might not be significant based on their respective uncertainties of approximately 0.04 and 0.02 , at certain locations in the flight leg the difference between them exceeds 0.06 . One possible reason for this difference might be that RSP retrievals are weighted towards the first optical depth of the cloud, which is close to the MAS $11 \mu \mathrm{m}$ brightness temperature cloud-top heights (see Sect. 2.1), whereas the CIN measurements are obtained deeper in the cloud. Indeed, vertically resolved CIN measurements in clouds sampled on 7 and 21 July as presented in Sects. 3.2 and 3.4, respectively, (see also Garrett et al., 2005) suggest a positive dependence of asymmetry parameter with altitude, although the dependence is weak. Also lidar depolarization profiles slightly increase above about $13.5 \mathrm{~km}$ (Noel et al., 2004), which might indicate a change in particle habit. Furthermore, Gayet et al. (2012) observed un- usually high concentrations of small chain-like aggregates of frozen droplets near the top of an overshooting deep convective cloud during the CIRCLE- 2 experiment, and determined their asymmetry parameters to be about 0.78 using a method comparable to the CIN retrievals here. However, no evidence of such aggregates of frozen droplets are seen in the CPI images acquired in this cloud system as discussed below. Alternatively, the RSP asymmetry parameter retrievals could be systematically biased high. For some of the compact particle habits used to evaluate the retrieval method in Part 1, asymmetry parameters are biased systematically by up to 0.04 . Furthermore, although the method was tested using a large range of possible particle habits, the shapes used in the evaluation might not represent the ice crystals occurring in the cloud observed here and greater biases than seen in Part 1 might occur. Moreover, as noted in Part 1, the look-up table used in the current application of the method is solely based 


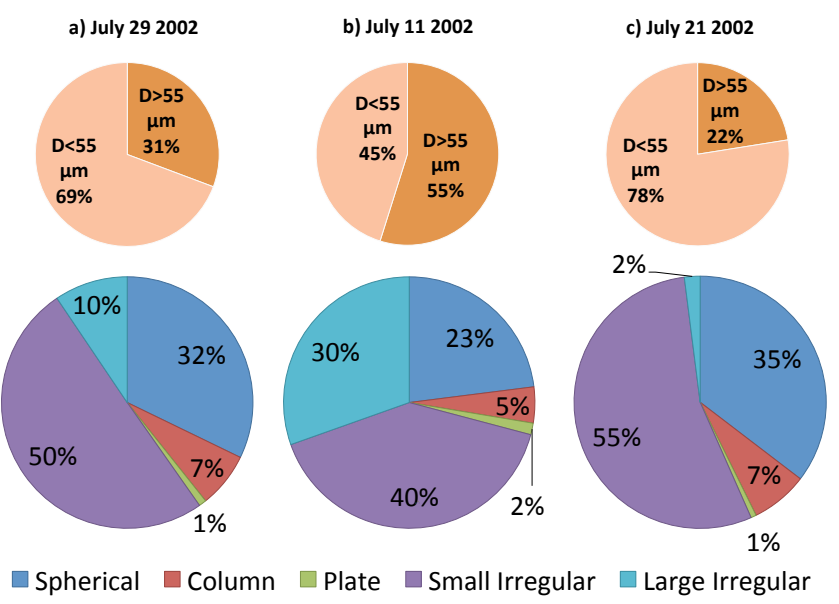

Fig. 4. Percentages of contribution to the total surface area from ice crystals with a maximum diameter smaller and larger than $55 \mu \mathrm{m}$ as determined by the CPI on the WB-57 (top pie diagrams), and percentages of CPI classifications according to total surface area (lower multi-colored pie diagrams, Lawson et al., 2001) for (a) 29 July (time $t=71.2-71.4 \mathrm{ks} \mathrm{UTC}$, height $h=12.5 \mathrm{~km}$ ); (b) 11 July $(t=67.2-67.4 \mathrm{ks} \mathrm{UTC}, h=13.2 \mathrm{~km})$; and (c) 21 July $(t=68.5-$ $68.6 \mathrm{ks}$ UTC, $h=14.1 \mathrm{~km})$.

on the geometric optics approximation, which may not apply if very small particles (with size parameters below about 100) dominate in the observed cloud. Furthermore, the scattering properties of small ice crystals are highly uncertain (e.g., Ulanowski et al., 2006; Um and McFarquhar, 2009). Further research on the validity of relying on geometrics optics to produce the LUTs is needed. We note that ice crystal effective radii retrieved using GOES-8 (Minnis et al., 1995), collocated with the Citation aircraft, range from $25 \mu \mathrm{m}$ to $40 \mu \mathrm{m}$ (not shown) and are therefore expected to be large enough for the geometrics optics approximation to be valid. As an alternative explanation for the difference between CIN and RSP retrievals, we speculate that the CIN data might be biased low, owing to ice shattering or other problems caused by the rather extreme environment within this cloud system. However, the potential effect of shattering on CIN retrievals of asymmetry parameters is difficult to quantify, as discussed in Sect. 2.4.

Ice habit classifications from the CPI on the WB-57, sampling the cloud at approximately $12.5 \mathrm{~km}$, show that small irregular and spherical particles dominated the total surface area in the cloud top (Fig. 4a; see also Noel et al., 2004). (Note that the term "spherical" is used for anything that appears roughly circular on the 2-D images and does not imply perfect ice spheres. Moreover, the CPI resolution is insufficient to detect crystal details smaller than about $3 \mu \mathrm{m}$.) The small irregular particles appear to be either compact crystals with aspect ratios near unity or distorted aggregates of columns and plates in the CPI images, as shown in Fig. 5 (see more images in Noel et al., 2004). Furthermore, particles

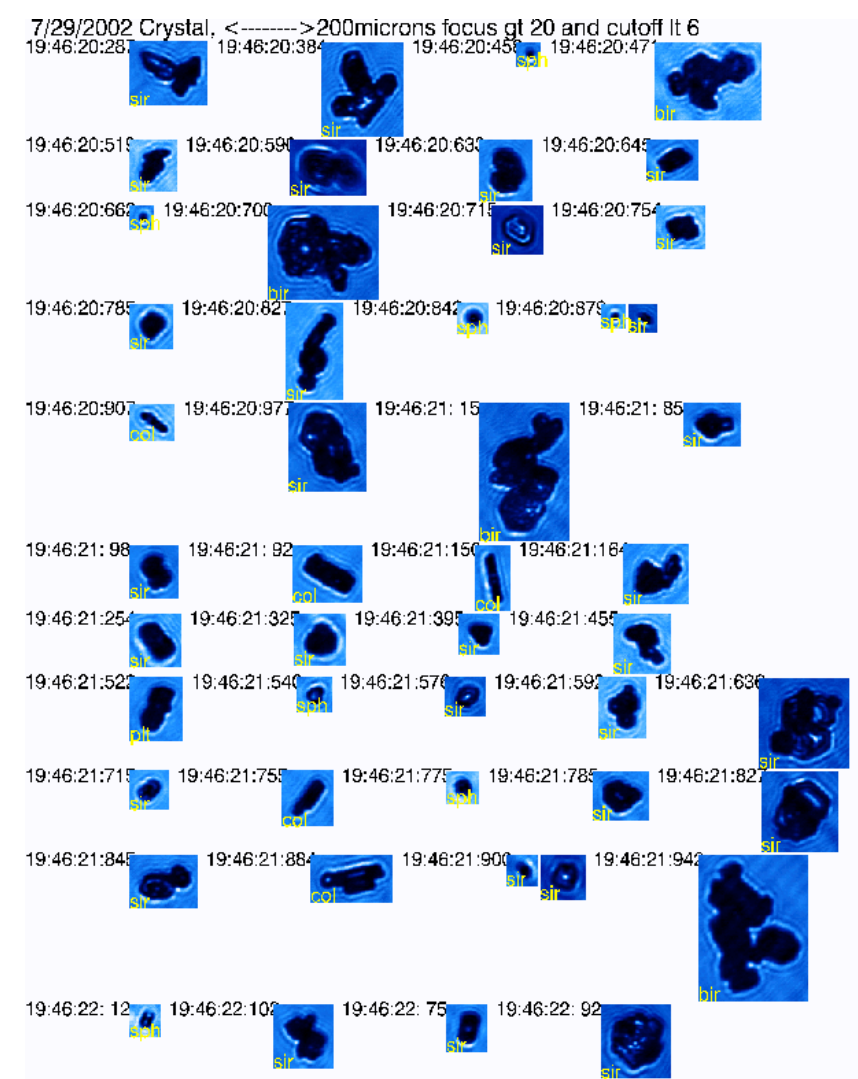

Fig. 5. Typical CPI images taken in the 29 July case on the WB-57.

with maximum dimensions smaller than $55 \mu \mathrm{m}$, which are generally assumed to be quasi-spherical, contributed $69 \%$ of the surface area measured by the CPI (Fig. 4a). Thus, the distorted particles with aspect ratios near unity retrieved by the RSP appear qualitatively consistent with these CPI statistics. We consider this consistency as more of a corroboration than a confirmation, since the CPI data measurements are merely two-dimensional projections and suffer from sampling biases as well as possible shattering effects (e.g. Korolev and Isaac, 2003; Korolev et al., 2011). The RSP results are also consistent with the dominance of irregular particles with aspect ratios near unity in cloud tops derived from lidar depolarization measurements (Noel et al., 2004). Furthermore, rough crystals were also found to be consistent with measurements made by the Cloud and Aerosol Spectrometer (CAS) throughout the CRYSTAL-FACE campaign (Baumgardner, 2005).

\subsection{July 2002}

On 7 July 2002, several storms developed off or near the west coast of southern Florida at around 16:00-17:00 UTC and merged some hours later (Li et al., 2004; Evans et al., 2005), when they were sampled by all aircraft involved in the CRYSTAL-FACE campaign (Fig. 2d). The RSP retrievals for the Proteus flight leg around 19:00 UTC in anvil aged by 


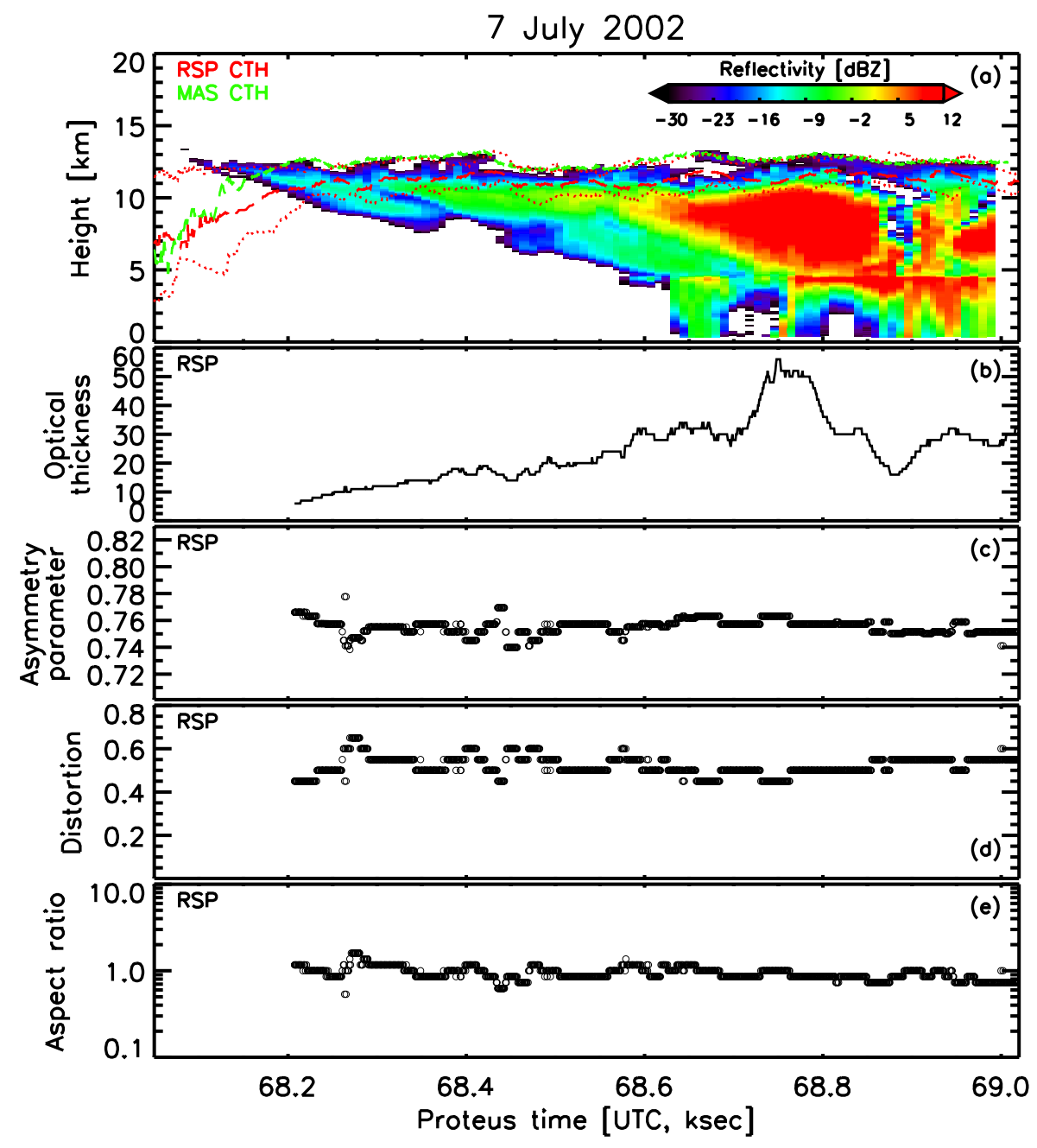

Fig. 6. Same as Fig. 3 but for 7 July and without CIN retrievals.

roughly $1.5 \mathrm{~h}$ are shown in Fig. 6, along with CRS radar reflectivity and MAS $11 \mu \mathrm{m}$ brightness temperature heights (Fig. 6a). This case was selected because the Citation aircraft carrying the CIN performed a spiral maneuver in the system at around 20:00 UTC, allowing a vertical profile of CIN measurements. Unfortunately, no CPI classifications or images are available. The data from the ER-2 and Citation were shifted and stretched/squeezed in time according to the flight paths and by matching features in the data. The radar reflectivities shown in Fig. 6a resemble those measured on 29 July (Fig. 3a) with a thick anvil that has a top near $12 \mathrm{~km}$ and high reflectivities extending down to the surface at some locations, indicative of precipitation. The mean solar zenith and relative azimuth angles corresponding to the RSP measurements for this case are $22^{\circ}$ and $50^{\circ}$, respectively.

Figure 6a shows cloud-top heights retrieved by RSP varying around $12 \mathrm{~km}$, which is consistent with the radar data. The difference between minimum and maximum cloud-top heights retrieved with the Rayleigh method (Sect. 2.2) is somewhat greater than in the previous case, presumably owing to the more heterogeneous cloud top. MAS $11 \mu \mathrm{m}$ brightness temperature heights are about $1 \mathrm{~km}$ higher than the median height from the Rayleigh method but are close to the maximum Rayleigh height.

Optical thicknesses (Fig. 6b) range from 1 to about 55 . Asymmetry parameters (Fig. 6c) range from 0.74 to 0.77 with a median of 0.76 . Aspect ratios (Fig. 6e) are again close to unity with a median of 0.86 , and the median distortion is 0.5 (Fig. 6d).

The extinction, optical depth and asymmetry parameters derived from CIN data acquired during the Citation spiral are shown in Fig. 7. The optical depth is calculated by vertically integrating median extinction values in $100 \mathrm{~m}$ altitude bins (cf. Garrett et al., 2005). Extinction values (Fig. 7a) are substantially smaller than those obtained on 29 July (Fig. 3b). The optical thickness derived from CIN is 92, which is substantially greater than the maximum optical thickness measured in the same cloud by RSP $(\sim 55)$. This discrepancy 


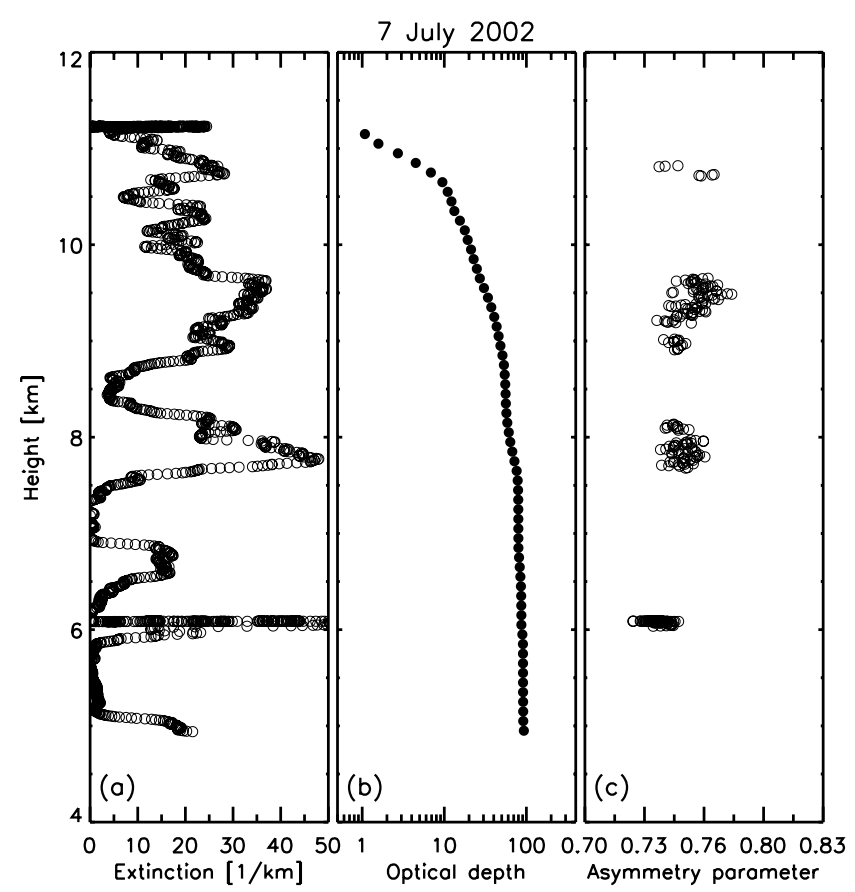

Fig. 7. CIN retrievals of extinction (a); optical depth (b); and asymmetry parameter (c) for data collected during the spiral of the Citation aircraft on 7 July 2002.

might be attributable to the facts that the sampled storm was quickly evolving and that the CIN and RSP measurements were obtained at a $1 \mathrm{~h}$ time difference and at different locations. At cloud top, asymmetry parameters retrieved by the CIN range from 0.74 to 0.77 , with a median of 0.76 that, in contrast to the previous case, compares remarkably well with the RSP retrievals. Furthermore, asymmetry parameters from the CIN show a slight increase with height, which might explain part of the discrepancy between asymmetry parameters retrieved by the CIN and RSP on 29 July, as discussed in Sect. 3.1. As particle size generally increases with decreasing height (Lawson et al., 2010; van Diedenhoven et al., 2012b) and particle aspect ratio is expected to increase somewhat with size (Auer and Veal, 1970; Korolev and Isaac, 2003), asymmetry parameters might be expected to increase with decreasing height rather than decrease, as found here. We speculate that the slight increase of asymmetry parameter with decreasing height might result from an increase of particle distortion or surface roughness.

\subsection{July 2002}

On 11 July 2002, storms developed at around 16:00 UTC on Florida's southeast coast (Fig. 2b) with outflow advecting westward (Chepfer et al., 2005; Lopez et al., 2006). Here we focus only on the northern storm since not all data are available for the southern storm. As seen in Fig. 8a, at around 18:30 UTC the anvil, aged by roughly $1.5 \mathrm{~h}$, generally ex- tends from $8-15 \mathrm{~km}$ altitude (Lopez et al., 2006). The data from the ER-2 and Citation used here lagged the RSP data by about 10 and $20 \mathrm{~min}$, respectively, and were shifted and stretched/squeezed in time according to the flight paths and by matching features in the data. The mean solar zenith and relative azimuth angles for this case are $13^{\circ}$ and $55^{\circ}$, respectively.

Cloud-top heights from RSP, MAS and the radar generally agree well (Fig. 8a). The difference between minimum and maximum cloud-top heights retrieved with the Rayleigh method (Sect. 2.2) is somewhat greater than for the 29 July case, presumably owing to the more heterogeneous cloud top. At the edge of the cloud around $65.7 \mathrm{ks}$ UTC, this difference exceeded our threshold for performing RSP retrievals $(3 \mathrm{~km}$, see Sect. 2.2). At around $61.15 \mathrm{ks}$ UTC, the Proteus started to perform a turn, leading to increasingly underestimated cloud-top heights owing to changing aircraft attitude not accounted for in our data processing. Figure 8a also shows that the Citation flew at about $9 \mathrm{~km}$ and only sampled the cloud when the bottom dropped below that altitude.

Optical thicknesses generally ranged from 5 to 40 and correlate with radar reflectivity (Fig. 8b). At the location where the CIN sampled the bottom of the cloud, extinction values up to $100 \mathrm{~km}^{-1}$ occur and also correlate with radar reflectivity.

Retrieved asymmetry parameters (Fig. 8c) are between about 0.72 and 0.8 and show more variation than seen in the 29 July case (Fig. 3c). Both RSP and CIN retrieve median asymmetry parameters of 0.76 for this case, which is slightly smaller than retrieved by RSP in the previous case. Although CIN sampled the very bottom of the cloud, vertical profiles presented by Garrett et al. (2005) and in Sects. 3.2 and 3.4 show weak variation of the asymmetry parameter with altitude. Median distortion is 0.7 , which is the upper limit in our LUT, and substantially greater than distortion values retrieved in the 29 July case. The retrieved aspect ratios (Fig. 8e) with a median value of 0.33 are also considerably more different from unity than seen in the previous case and show more variability.

The clear distinctions in particle aspect ratio and distortion between the 29 and 11 July cases seem also to be reflected in the CPI images (Figs. 5 and 9) and classifications (Fig. 4a, b), with substantially more large aggregates sampled on 11 July. Moreover, $55 \%$ of the total surface area was attributed to particles larger than $55 \mu \mathrm{m}$ on 11 July, versus $31 \%$ on 29 July (Fig. 4a, b). The aggregates sampled by the CPI on 11 July (Fig. 9) strongly resemble rough aggregates of mainly plates, which is qualitatively consistent with the low aspect ratios retrieved by RSP. Aggregates of plates were also found to be prevalent in dissipating tropical anvil clouds sampled during the TWP-ICE campaign (Um and McFarquhar, 2009). 


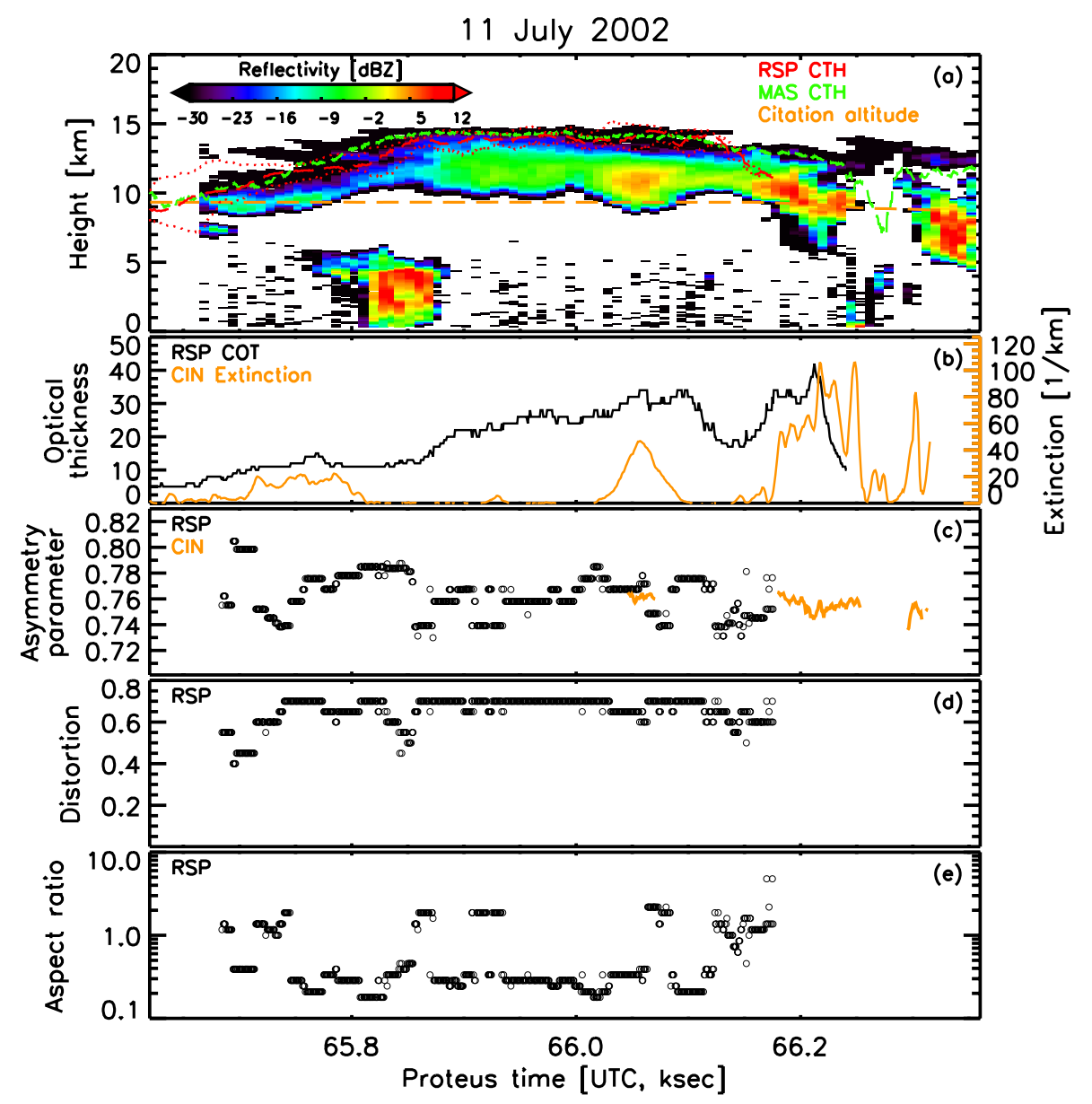

Fig. 8. Same as Fig. 3 but for 11 July.

\subsection{July 2002}

Several storms developed on the east coast of Florida at around 18:00 UTC on 21 July, 2002 and relatively strong winds advected the anvils southeastwards off the coast, where they were sampled by the Proteus, Citation and WB57 aircraft. No radar or MAS measurements are available since the ER-2 did not fly that day but we include the case because the Citation performed a spiral in the cloud. The structure and evolution of this system have been discussed in detail by Garrett et al. (2005). Around the time the RSP and $\mathrm{CIN}$ measurements were obtained, the sampled anvil started to detach from the storm that generated it. The vertical extent of the anvil is similar to that sampled on 11 July $(8.5-14 \mathrm{~km}$; Garrett et al., 2005). The mean solar zenith and relative azimuth angles for the RSP data in this case are $24^{\circ}$ and $68^{\circ}$, respectively.

Cloud-top heights vary over the anvil from about 10 to $14 \mathrm{~km}$ (Fig. 10a). The highest cloud tops occur at the downwind, southern end of the storm ( $69.35 \mathrm{ks}$ UTC) and strongly drop after about $69.4 \mathrm{ks}$ UTC. The large differences between minimum and maximum cloud-top heights are retrieved by the RSP for times before $69.12 \mathrm{ks}$ UTC, presumably because of uncertainties in the angle aggregation owing to the relatively sharp edge of the cloud, as discussed in Sect. 2.2. Retrieved optical thicknesses peak at about 20 (Fig. 10b). Interestingly, the optical thickness peaks at a different location than the cloud-top height, indicating a sheared system. Near-collocated cloud-top heights retrieved using GOES-8 (Sherwood, 2004) compare well with the RSP retrievals (not shown).

Asymmetry parameters range from 0.74 to 0.78 with a median value of 0.76 (Fig. 10c). The smallest values are seen in the optically thin, highest part of the cloud. Note that sunglint inhibited retrievals after about $69.38 \mathrm{ks}$ UTC, while retrievals before $69.12 \mathrm{ksUTC}$ are not performed since the uncertainty in cloud-top height exceeded our threshold of $3 \mathrm{~km}$. Retrieved aspect ratios are close to unity with a median value of 1.2 , while distortion values are around 0.4-0.6 with a median of 0.5 (Fig. 10d, e). These values are comparable with the retrievals obtained for the 29 July case, although asymmetry parameters are slightly smaller $(0.02)$ here. Also, the distribution of CPI habit classifications is very similar 


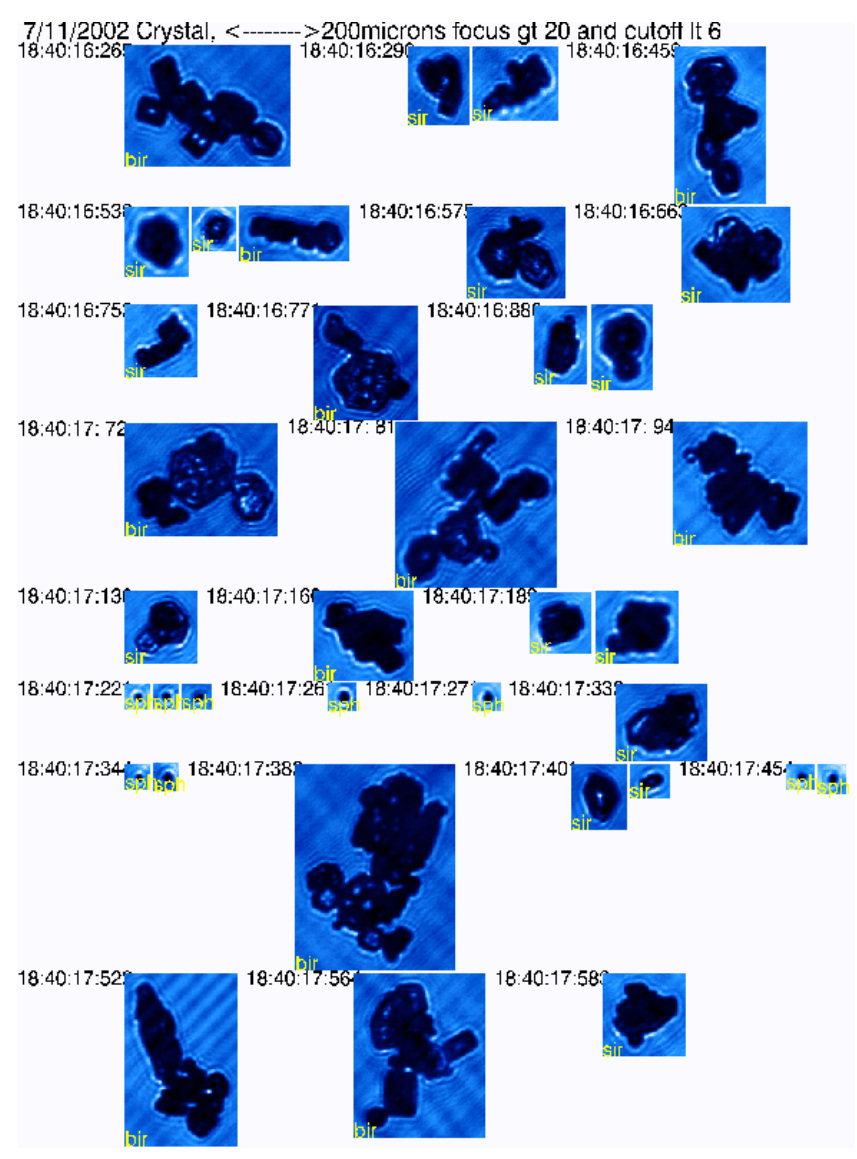

Fig. 9. Typical CPI images taken in the 11 July case on the WB-57.

to that obtained on 29 July (Fig. 3c). Individual CPI images have been shown by Garrett et al. (2005), and those acquired near the cloud top appear similar to those obtained on 29 July, which are shown in Fig. 5.

The vertical profile of extinction, optical depth and asymmetry parameters derived from the CIN measurements obtained around 19:30 UTC are shown in Fig. 11. The optical depth is again calculated by vertically integrating median extinction values in $100 \mathrm{~m}$ altitude bins. The same profiles were shown by Garrett et al. (2005). However, extinction and optical thickness values shown here are about $20 \%$ greater than those in Garrett et al. (2005), while asymmetry parameters are about 0.05 lower, owing to a correction factor applied to the calibration parameters used in the 2005 paper. Thus, Fig. 11 can be considered a correction to (part of) Fig. 5 in Garrett et al. (2005). The optical thickness derived from the CIN extinction measurements is 27 , which is somewhat greater than the maximum value retrieved by the RSP (Fig. 10b). A qualitatively consistent discrepancy was found for the spiral obtained on 7 July (Sect. 3.2).

The asymmetry parameters retrieved by the CIN show a slight increase with height and are about 0.73 in the top of the cloud, which is smaller than the median values retrieved by the RSP (0.76) although comparable with the low- est values retrieved by RSP (0.74). Also, the median values retrieved by the RSP and CIN statistically agree within their combined uncertainties. Garrett et al. (2005) noted that a spiral performed by the WB-57 in the same anvil between 12.5 and $14.5 \mathrm{~km}$ still detected cloud at these altitudes, but only with extinction values below $0.2 \mathrm{~km}^{-1}$ and a total optical depth of about 0.1 . These cloud particles were interpreted as a separate thin tropopause cirrus layer by Garrett et al. (2005). However, the gradual increase of cloud-top height at 69.1-69.4 ksec and the sudden drop thereafter, as seen in Fig. 10a, suggest a single cloud system with top heights ranging from about 10 to $14 \mathrm{~km}$. Unfortunately, the WB-57 CIN instrument was not fully functioning and was not able to retrieve asymmetry parameters. Since the Citation did not reach the very top of the cloud at all locations, it is possible that the difference between asymmetry parameters retrieved by CIN and RSP are partly attributable to vertical variation if the asymmetry parameters in the very top are substantially greater than those at the altitudes of the CIN measurements. Furthermore, possible biases in RSP and CIN retrievals, as discussed in Sect. 3.1, could also be causing part of this difference.

\subsection{Discussion}

The asymmetry parameter, distortion and aspect ratios retrieved by RSP for all four cases are compared in Table 1, along with the CIN asymmetry parameters and CPI classifications. Median asymmetry parameters retrieved by the RSP range from 0.76 to 0.78 , with the maximum values obtained on 29 July. Greater variability (interquartile ranges) are seen for the detached anvils (11th and 21st July) compared to the thick convective clouds (29 and 7 July) with the retrievals for the 29th being the least variable. Between the four cases studied here, the CIN measurements show somewhat more variability, clumping into two cases near 0.73 and two others near 0.76 .

Although the difference in median asymmetry parameters between the 29th and other cases is not below the estimated retrieval uncertainty of 0.04 , the 29 July case stands out with large optical thickness and an apparently overshooting top. Furthermore, elevated dust layers were observed on 29 July (Sassen et al., 2003) and this storm had exceptionally strong lightning activity (Ott et al., 2010); both may have an effect on ice particle growth (e.g. Fridlind et al., 2004; Sherwood et al., 2006). The 29 July case also stands out because of the large difference between asymmetry parameters retrieved by the RSP and the CIN. Vertical variation of the asymmetry parameter may explain part of the difference between CIN and RSP retrievals in this case.

Another case that stands out is that of 11 July, owing to its relatively low retrieved aspect ratios and high distortion values. Although the median asymmetry parameter is similar to the other cases, the retrievals show substantially more variation over the sampled anvil. This case also stands out in 


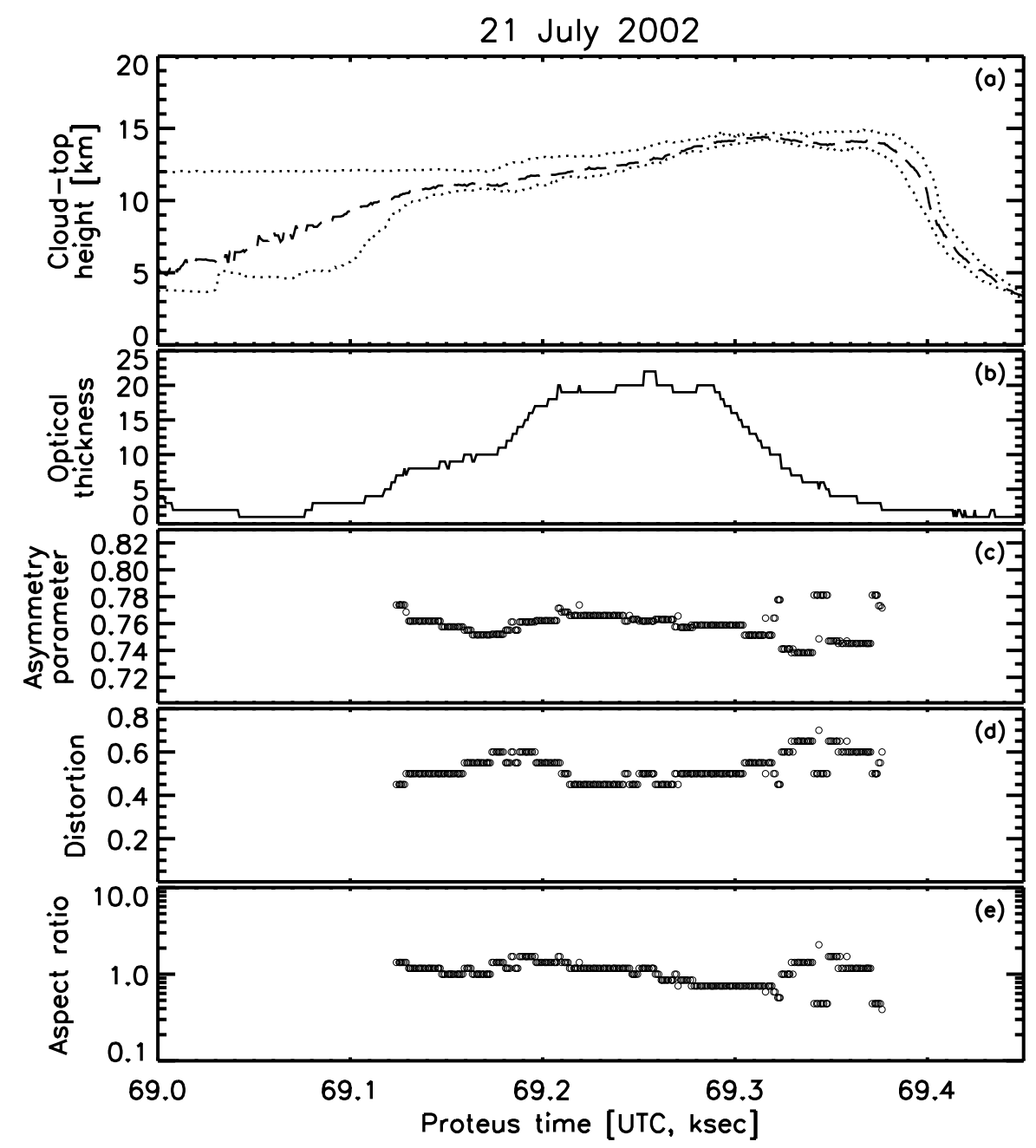

Fig. 10. RSP retrieval as a function of time for 21 July. (a) Cloud-top height with minimum and maximum retrieved heights in dotted lines; (b) cloud optical thickness; (c) asymmetry parameter, (d) distortion parameter; and (e) aspect ratios.

the fraction of total surface area contributed by particles with maximum dimensions larger than $55 \mu \mathrm{m}$, as measured by the CPI, as well as substantially fewer spherical particles and more large irregular particles appearing in the CPI images. This is the only storm in our study that evolved over land, which may have affected its dynamical structure (Futyan and Del Genio, 2007) and thereby the ice habits.

Ambient temperatures and ice supersaturation levels are known to influence the aspect ratios of the ice crystals and whether crystals grow as plate- or column-like (e.g. Bailey and Hallett, 2009). For most of the cases studied here, plate-like aspect ratios $(<1)$ and column-like aspect ratios $(>1)$ are retrieved over the observed storms, consistent with varying mixtures of cloud-top particle shapes, including aggregates with both column and plate elements (Fig. 5), which could be indicative of varying crystal formation and evolution histories. Only for the 29 July case are aspect ratios greater than unity always retrieved, indicating the consistent predominance of column-like crystals at cloud top.

\section{Conclusions}

In this paper, a new method to retrieve ice cloud asymmetry parameters from multi-directional polarized reflectance measurements described in Part 1 (van Diedenhoven et al., 2012a) is applied to measurements of the airborne Research Scanning Polarimeter (RSP) obtained during the CRYSTALFACE campaign in 2002. The retrieval procedure assumes simple hexagonal columns and plates provide adequate proxies for the scattering properties of complex ice structures. A look-up table of polarized reflectances is calculated using hexagonal columns and plates with a virtually continuous selection of aspect ratios and microscale distortion parameters, and between the values therein the closest match is determined with multi-directional polarized reflectance 
Table 1. Median retrieved asymmetry parameters from RSP and CIN, median aspect ratios and median distortion from the RSP, CPI areal fraction of particles larger than $55 \mu \mathrm{m}$, and CPI classifications dominating particle area. Interquartile ranges are given in brackets.

\begin{tabular}{llllllll}
\hline $\begin{array}{l}\text { Case } \\
\text { study }\end{array}$ & Cloud sampled & RSP $g$ & CIN $g$ & $\begin{array}{l}\text { RSP } \\
\text { aspect ratio }\end{array}$ & $\begin{array}{l}\text { RSP } \\
\text { distortion }\end{array}$ & $\begin{array}{l}\text { CPI } \\
D>55 \mu m\end{array}$ & Main CPI classes ${ }^{\text {a }}$ \\
\hline 29 July & Deep convection & $0.782( \pm 0.005)$ & $0.732( \pm 0.014)$ & $1.6( \pm 0.3)$ & $0.45( \pm 0.05)$ & $31 \%$ & SI (50\%), SPH (32\%) \\
7 July & Deep convection & $0.757( \pm 0.008)$ & $0.762( \pm 0.019)^{\mathrm{b}}$ & $0.86( \pm 0.1)$ & $0.50( \pm 0.05)$ & N/A & N/A \\
11 July & Detached anvil & $0.767( \pm 0.024)$ & $0.757( \pm 0.008)$ & $0.33( \pm 1)$ & $0.70( \pm 0.1)$ & $55 \%$ & SI (40\%), LI (30\%) \\
21 July & Detached anvil & $0.759( \pm 0.012)$ & $0.725( \pm 0.012)^{\mathrm{b}}$ & $1.2( \pm 0.4)$ & $0.50( \pm 0.1)$ & $22 \%$ & SI (55\%), SPH (35\%) \\
\hline
\end{tabular}

${ }^{\text {a }}$ LI denotes large irregular; SI denotes small irregular; SPH denotes spherical.

$\mathrm{b}$ Values in the top $1 \mathrm{~km}$ of CIN measurements.

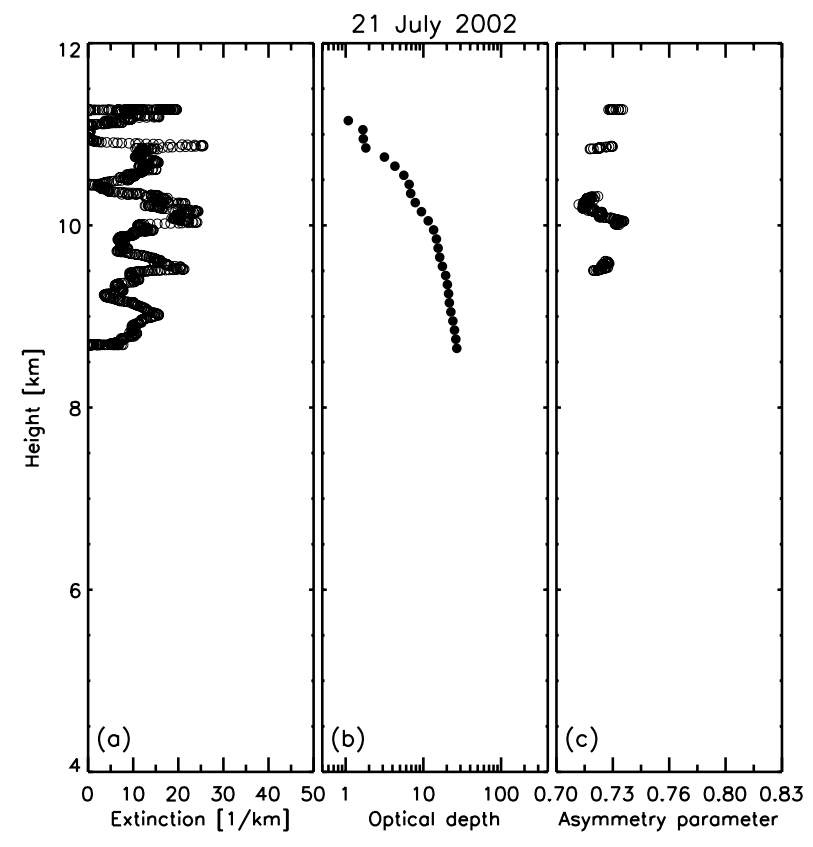

Fig. 11. Same as Fig. 7 but for 21 July.

measurements. The asymmetry parameter of the hexagonal particle that yields the closest match to the measurements is considered the retrieved value. As discussed in Part 1, this method yields asymmetry parameters with an accuracy of about $5 \%$, or 0.04 in absolute terms. Additionally, an estimate is established for the microscale surface distortion of the ice crystals and the effective aspect ratios of their components. Cloud optical thickness and cloud-top heights are also obtained from the RSP measurements in this study.

Four case studies were analyzed: two cases of thick convective clouds and two cases of thinner (detached) anvil cloud layers. Median asymmetry parameters retrieved by the RSP range from 0.76 to 0.78 . In general, the detached anvil clouds showed somewhat more variation in retrieved asymmetry parameter than the thick convective clouds. In all cases the measurements indicate roughened or distorted ice crystals, consistent with previous findings. Retrieved aspect ratios in three of the cases were found to be close to unity, indi- cating that compact particles dominate the radiation, qualitatively consistent with CPI images where available. Retrievals for the anvil sampled on 11 July indicated ice crystals consisting of plate-like components with aspect ratios around 0.3 , consistent with the increased number of aggregates of plates seen in the CPI images obtained in this cloud layer.

Retrieved asymmetry parameters were compared to those determined by the Cloud Integrating Nephelometer (CIN), which obtained in situ measurements in the same cloud layers. For one case sampling a thick convective cloud and one case sampling an anvil cloud, the median values of asymmetry parameter retrieved by CIN and RSP agree within 0.01 . For the two other cases, however, RSP asymmetry parameters are systematically higher than those obtained by the CIN by about $0.03-0.05$. Part of this bias might be explained by vertical variation of the asymmetry parameter, as the RSP retrievals are estimated to be weighted towards the first optical depth of the cloud top, while the CIN probed deeper in the cloud. Also, the CIN measurements might have been affected by ice shattering on the probe.

Overall, the retrieved asymmetry parameters, aspect ratios, distortion values and cloud heights are largely consistent with the other near-collocated in situ and remote sensing measurements and with previous findings in similar clouds. Some issues remain, however, such as the discrepancy between RSP and CIN asymmetry parameters in some cases, the effect of vertical variation of ice habits on the retrievals and possible effects from the neglect of three-dimensional radiative transfer. More data analysis and studies with simulated measurements are needed. Unfortunately, the RSP data presented here represent the only airborne multi-directional polarization data over ice clouds collocated with relevant other aircraft data available to date. Moreover, the RSP was mounted on the Proteus aircraft, which was not very stable and no record about its attitude is available, adding an additional uncertainty in the asymmetry parameter retrieval of about 0.01 and making part of the flights unsuited for retrievals. Future high-altitude flights of the RSP mounted on the ER-2 aircraft are expected to yield excellent data to further evaluate the presented method. Additionally, as shown in Part 1, the method can be applied to POLDER measurements, which may allow evaluation of the method using in 
situ and other remote sensing data obtained from other campaigns (e.g. TWP-ICE, TC4). Furthermore, in order to provide a more rigorous evaluation of the capabilities of the approach presented here, in situ instruments are required that that are not contaminated by shattering artifacts and possibly sample the scattering matrix elements across a wide range of scattering angles.

For the effective radii of the ice present in the tops of the studied clouds ( $20-50 \mu \mathrm{m}$, as indicated by GOES-8), typical parameterizations of ice crystal asymmetry parameters yield values from 0.78 to 0.83 (e.g. Fu, 1996; Chou et al., 2002; McFarquhar et al., 2002), which is generally larger than retrieved for the case studies in this paper, although some other parameterizations yield lower asymmetry parameters (e.g., Mitchell et al., 1996; Edwards et al., 2007). The retrieved asymmetry parameters are also considerably smaller than those assumed in current satellite retrievals of ice cloud optical thickness and ice crystal effective radius (Baum et al., 2005 b). As shown by, for example, van Diedenhoven et al. (2012b), such retrievals of ice crystal effective radius depend on the assumed ice model, primarily on the assumed asymmetry parameter. Although RSP provides the shortwave infrared measurements that allow simultaneous retrieval of ice crystal effective radius (Nakajima and King, 1990), we did not include these retrievals in the present study. Simultaneous retrievals of asymmetry parameter, effective radius and cloud optical thickness from RSP measurements would provide an ideal means to study the sensitivity of effective radius retrievals to variations in asymmetry parameter.

Acknowledgements. This material is based upon work supported by the NASA ROSES program under grant number NNX11AG81G and by the NASA Radiation Science Program managed by Hal Maring in support of the SEAC4RS field experiment. We thank Andrzej Wasilewski for his help interpreting the level-1 RSP data.

Edited by: Q. Fu

\section{References}

Alexandrov, M. D., Cairns, B., Emde, C., Ackerman, A. S., and van Diedenhoven, B.: Accuracy assessments of cloud droplet size retrievals from polarized reflectance measurements by the research scanning polarimeter, Remote Sens. Environ., 125, 92111, doi:10.1016/j.rse.2012.07.012, 2012.

Auer, A. and Veal, D.: The dimension of ice crystals in natural clouds, J. Atmos. Sci, 27, 919-926, 1970.

Auriol, F., Gayet, J.-F., Febvre, G., Jourdan, O., Labonnote, L., and Brogniez, G.: In situ observation of cirrus scattering phase functions with $22^{\circ}$ and $46^{\circ}$ halos: cloud field study on 19 February 1998, J. Atmos. Sci., 58, 3376-3390, doi:10.1175/15200469(2001)058<3376:ISOOCS > 2.0.CO;2, 2001.

Bailey, M. P. and Hallett, J.: A comprehensive habit diagram for atmospheric ice crystals: confirmation from the laboratory, AIRS II, and other field studies, J. Atmos. Sci., 66, 2888-2899, doi:10.1175/2009JAS2883.1, 2009.
Baran, A. J.: A review of the light scattering properties of cirrus, J. Quant. Spectrosc. Rad. Transf., 110, 1239-1260, doi:10.1016/j.jqsrt.2009.02.026, 2009.

Baran, A. J., Shcherbakov, V. N., Baker, B. A., Gayet, J. F., and Lawson, R. P.: On the scattering phase-function of nonsymmetric ice-crystals, Q. J. R. Meteor. Soc., 131, 2609-2616, doi:10.1256/qj.04.137, 2005.

Baum, B. A., Heymsfield, A. J., Yang, P., and Bedka, S. T.: Bulk scattering properties for the remote sensing of ice clouds, Pt. I: Microphysical data and models, J. Appl. Meteor., 44, 1885, doi:10.1175/JAM2308.1, 2005a.

Baum, B. A., Yang, P., Heymsfield, A. J., Platnick, S., King, M. D., $\mathrm{Hu}$, Y. X., and Bedka, S. M.: Bulk scattering properties for the remote sensing of ice clouds, Pt. II: Narrowband models, J. Appl. Meteor., 44, 1896-1911, 2005b.

Baum, B. A., Yang, P., Heymsfield, A. J., Schmitt, C. G., Xie, Y., Bansemer, A., Hu, Y.-X., and Zhang, Z.: Improvements in shortwave bulk scattering and absorption models for the remote sensing of ice clouds, J. Appl. Meteor. Clim., 50, 1037-1056, doi:10.1175/2010JAMC2608.1, 2011.

Baumgardner, D.: The shapes of very small cirrus particles derived from in situ measurements, Geophys. Res. Lett., 32, L01806, doi:10.1029/2004GL021300, 2005.

Bodhaine, B. A., Wood, N. B., Dutton, E. G., and Slusser, J. R.: On rayleigh optical depth calculations, J. Atmos. Ocean. Tech., 16, 1854-1861, doi:10.1175/15200426(1999)016<1854:ORODC>2.0.CO;2, 1999.

Buriez, J., Vanbauce, C., and Parol, F.: Cloud detection and derivation of cloud properties from POLDER, Int. J. Remote Sens., 18, 2785-2813, doi:10.1080/014311697217332, 1997.

Cairns, B., Russell, E. E., and Travis, L. D.: Research scanning polarimeter: calibration and ground-based measurements, Proc. SPIE, 3754, 186-196, avaiable at: http://adsabs.harvard.edu/abs/ 1999SPIE.3754..186C, 1999.

Cairns, B., Russell, E. E., LaVeigne, J. D., and Tennant, P. M. W.: Research scanning polarimeter and airborne usage for remote sensing of aerosols, Proc. SPIE, 5158, 33-44, doi:10.1117/12.518320, 2003.

Cetrone, J. and Houze, R. A.: Leading and trailing anvil clouds of West African squall lines, J. Atmos. Sci., 68, 1114-1123, doi:10.1175/2011JAS3580.1, 2011.

Chepfer, H., Noel, V., Minnis, P., Baumgardner, D., Nguyen, L., Raga, G., McGill, M. J., and Yang, P.: Particle habit in tropical ice clouds during CRYSTAL-FACE: comparison of two remote sensing techniques with in situ observations, J. Geophys. Res., 110, D16204, doi:10.1029/2004JD005455, 2005.

Chou, M.-D., Lee, K.-T., and Yang, P.: Parameterization of shortwave cloud optical properties for a mixture of ice particle habits for use in atmospheric models, J. Geophys. Res., 107, 4600, doi:10.1029/2002JD002061, 2002.

Chowdhary, J., Cairns, B., and Travis, L. D.: Case studies of aerosol retrievals over the ocean from multiangle, multispectral photopolarimetric remote sensing data, J. Atmos. Sci., 59, 383-397, doi:10.1175/1520-0469(2002)059<0383:CSOARO > 2.0.CO;2, 2002.

Coakley, J. A. J. and Chylek, P.: The two-stream approximation in radiative transfer: including the angle of the incident radiation, J. Atmos. Sci., 32, 409-418, 1975. 
Cox, C. and Munk, W.: Measurement of the roughness of the sea surface from photographs of the sun's glitter, J. Opt. Soc. America, 44, 838-850, doi:10.1364/JOSA.44.000838, 1954.

Cox, C. and Munk, W.: Slopes of the sea surface deduced from photographs of sun glitter, Bull. Scripps Inst. Oceanogr., 6, 401-488, 1956.

de Haan, J., Bosma, P., and Hovenier, J.: The adding method for multiple scattering calculations of polarized light, Astron. Astroph., 183, 371-391, 1987.

Edwards, J., Havemann, S., Thelen, J.-C., and Baran, A.: A new parametrization for the radiative properties of ice crystals: Comparison with existing schemes and impact in a GCM, Atmos. Res., 83, 19-35, doi:10.1016/j.atmosres.2006.03.002, 2007.

Evans, K. F., Wang, J. R., Racette, P. E., Heymsfield, G., and Li, L.: Ice cloud retrievals and analysis with the compact scanning submillimeter imaging radiometer and the cloud radar system during CRYSTAL-FACE, J. Appl. Met., 44, 839-859, doi:10.1175/JAM2250.1, 2005.

Francis, P. N., Jones, A., Saunders, R. W., Shine, K. P., Slingo, A., and Sun, Z.: An observational and theoretical study of the radiative properties of cirrus: some results from ICE'89, Q. J. R. Meteorol. Soc, 120, 809-848, doi:10.1002/qj.49712051804, 1994.

Fridlind, A. M., Ackerman, A. S., Jensen, E. J., Heymsfield, A. J., Poellot, M. R., Stevens, D. E., Wang, D., Miloshevich, L. M., Baumgardner, D., Lawson, R. P., Wilson, J. C., Flagan, R. C., Seinfeld, J. H., Jonsson, H. H., VanReken, T. M., Varutbangkul, V., and Rissman, T. A.: Evidence for the predominance of midtropospheric aerosols as subtropical anvil cloud nuclei., Science, 304, 718-22, doi:10.1126/science.1094947, 2004.

$\mathrm{Fu}, \mathrm{Q}$.: An accurate parameterization of the solar radiative properties of cirrus clouds for climate models., J. Clim., 9, 2058-2082, doi:10.1175/1520-0442(1996)009<2058:AAPOTS > 2.0.CO;2, 1996.

$\mathrm{Fu}, \mathrm{Q}$.: A new parameterization of an asymmetry factor of cirrus clouds for climate models, J. Atmos. Sci., 64, 4140, doi:10.1175/2007JAS2289.1, 2007.

Futyan, J. M. and Del Genio, A. D.: Deep convective system evolution over Africa and the tropical atlantic, J. Clim., 20, 50415060, doi:10.1175/JCLI4297.1, 2007.

Garrett, T. J.: Comments on "Effective radius of ice cloud particle populations derived from aircraft probes", J. Atmos. Ocean. Tech., 24, 1495-1503, doi:10.1175/JTECH2075.1, 2007.

Garrett, T. J.: Observational quantification of the optical properties of cirrus cloud, in: Light Scattering Reviews 3, Springer Berlin Heidelberg, Berlin, Heidelberg, 3-26, doi:10.1007/978-3540-48546-9, 2008.

Garrett, T. J., Hobbs, P. V., and Gerber, H.: Shortwave, singlescattering properties of arctic ice clouds, J. Geophys. Res., 106, 15155-15172, doi:10.1029/2000JD900195, 2001.

Garrett, T. J., Gerber, H., Baumgardner, D. G., Thohy, C. H., and Weinstock, E. M.: Small, highly reflective ice crystals in low-latitude cirrus, Geophys. Res. Lett., 30, 10-13, doi:10.1029/2003GL018153, 2003.

Garrett, T. J., Navarro, B. C., Twohy, C. H., Jensen, E. J., Baumgardner, D. G., Bui, P. T., Gerber, H., Herman, R. L., Heymsfield, A. J., Lawson, P., Minnis, P., Nguyen, L., Poellot, M., Pope, S. K., Valero, F. P. J., and Weinstock, E. M.: Evolution of a Florida cirrus anvil, J. Atmos. Sci., 62, 2352, doi:10.1175/JAS3495.1, 2005.
Gayet, J. F., Crépel, O., Fournol, J. F., and Oshchepkov, S.: A new airborne polar nephelometer for the measurements of optical and microphysical cloud properties, Pt. I: Theoretical design, Ann. Geophys., 15, 451-459, doi:10.1007/s00585-997-0451-1, 1997.

Gayet, J.-F., Shcherbakov, V., Mannstein, H., Minikin, A., Schumann, U., Ström, J., Petzold, A., Ovarlez, J., and Immler, F.: Microphysical and optical properties of midlatitude cirrus clouds observed in the southern hemisphere during INCA, Q. J. R. Meteor. Soc., 132, 2719-2748, doi:10.1256/qj.05.162, 2006.

Gayet, J.-F., Mioche, G., Bugliaro, L., Protat, A., Minikin, A., Wirth, M., Dörnbrack, A., Shcherbakov, V., Mayer, B., Garnier, A., and Gourbeyre, C.: On the observation of unusual high concentration of small chain-like aggregate ice crystals and large ice water contents near the top of a deep convective cloud during the CIRCLE-2 experiment, Atmos. Chem. Phys., 12, 727-744, doi:10.5194/acp-12-727-2012, 2012.

Gerber, H., Takano, Y., Garrett, T. J., and Hobbs, P. V.: Nephelometer measurements of the asymmetry parameter, volume extinction coefficient, and backscatter ratio in arctic clouds, J. Atmos. Sci., 57, 3021-3034, 2000.

Hansen, J. E. and Travis, L. D.: Light scattering in planetary atmospheres, Space Sci. Rev., 16, 527-610, doi:10.1007/BF00168069, 1974.

Hess, M., Koelemeijer, R. B., and Stammes, P.: Scattering matrices of imperfect hexagonal ice crystals, J. Quant. Spectrosc. Rad. Transf., 60, 301-308, doi:10.1016/S0022-4073(98)000077, 1998.

Heymsfield, A. J., Schmitt, C., Bansemer, A., van Zadelhoff, G.-J., McGill, M. J., Twohy, C., and Baumgardner, D.: Effective radius of ice cloud particle populations derived from aircraft probes, J. Atmos. Ocean. Tech., 23, 361-380, doi:10.1175/JTECH1857.1, 2006.

Houze, R. A.: Structures of atmospheric precipitation systems: A global survey, Radio Sci., 16, 671-689, doi:10.1029/RS016i005p00671, 1981.

King, M. D., Platnick, S., Yang, P., Arnold, G. T., Gray, M. A., Riedi, J. C., Ackerman, S. A., and Liou, K.-N.: Remote sensing of liquid water and ice cloud optical thickness and effective radius in the Arctic: application of airborne multispectral MAS data, J. Atmos. Ocean. Tech., 21, 857-875, doi:10.1175/15200426(2004)021<0857:RSOLWA>2.0.CO;2, 2004.

Knobelspiesse, K., Cairns, B., Redemann, J., Bergstrom, R. W., and Stohl, A.: Simultaneous retrieval of aerosol and cloud properties during the MILAGRO field campaign, Atmos. Chem. Phys., 11, 6245-6263, doi:10.5194/acp-11-6245-2011, 2011.

Knobelspiesse, K., Cairns, B., Mishchenko, M., Chowdhary, J., Tsigaridis, K., van Diedenhoven, B., Martin, W., Ottaviani, M., and Alexandrov, M.: Analysis of fine-mode aerosol retrieval capabilities by different passive remote sensing instrument designs, Opt. Express, 20, 21457, doi:10.1364/OE.20.021457, 2012.

Korolev, A. V. and Isaac, G.: Roundness and aspect ratio of particles in ice clouds, J. Atmos. Sci., 60, 1795-1808, 2003.

Korolev, A. V., Emery, E. F., Strapp, J. W., Cober, S. G., Isaac, G. A., Wasey, M., and Marcotte, D.: Small ice particles in tropospheric clouds: fact or artifact? Airborne icing instrumentation evaluation experiment, Bull. Amer. Meteor. Soc., 92, 967-973, doi:10.1175/2010BAMS3141.1, 2011.

Lawson, R. P., Baker, B. A., Schmitt, C. G., and Jensen, T. L.: An overview of microphysical properties of Arctic clouds observed 
in May and July 1998 during FIRE ACE, J. Geophys. Res., 106, 14989-15014, doi:10.1029/2000JD900789, 2001.

Lawson, R. P., Jensen, E., Mitchell, D. L., Baker, B., Mo, Q., and Pilson, B.: Microphysical and radiative properties of tropical clouds investigated in TC4 and NAMMA, J. Geophys. Res., 115, D00J08, doi:10.1029/2009JD013017, 2010.

Li, L., Heymsfield, G. M., Racette, P. E., Tian, L., and Zenker, E.: A 94-GHz cloud radar system on a NASA high-altitude ER-2 aircraft, J. Atmos. Ocean. Tech., 21, 1378-1388, doi:10.1175/15200426(2004)021<1378:AGCRSO>2.0.CO;2, 2004.

Lopez, J. P., Fridlind, A. M., Jost, H.-J., Loewenstein, M., Ackerman, A. S., Campos, T. L., Weinstock, E. M., Sayres, D. S., Smith, J. B., Pittman, J. V., Hallar, A. G., Avallone, L. M., Davis, S. M., and Herman, R. L.: CO signatures in subtropical convective clouds and anvils during CRYSTAL-FACE: an analysis of convective transport and entrainment using observations and a cloud-resolving model, J. Geophys. Res., 111, D09305, doi:10.1029/2005JD006104, 2006.

Macke, A., Mueller, J., and Raschke, E.: Single scattering properties of atmospheric ice crystals, J. Atmos. Sci., 53, 2813-2825, 1996.

McFarquhar, G. M., Yang, P., Macke, A., and Baran, A. J.: A new parameterization of single scattering solar radiative properties for tropical anvils using observed ice crystal size and shape distributions, J. Atmos. Sci., 59, 2458-2478, 2002.

Minnis, P., Kratz, D., and Coakley, J.: Clouds and the Earth's Radiant Energy System (CERES) algorithm theoretical basis document, vol. 3: cloud analyses and radiance inversions (subsystem 4), NASA RP 1376, 3, 135-176, 1995.

Minnis, P., Yost, C. R., Sun-Mack, S., and Chen, Y.: Estimating the top altitude of optically thick ice clouds from thermal infrared satellite observations using CALIPSO data, Geophys. Res. Lett., 35, L12801, doi:10.1029/2008GL033947, 2008.

Mishchenko, M. I. and Sassen, K.: Depolarization of Lidar Returns by Small Ice Crystals: An Application to Contrails, Geophys. Res. Lett., 25, 309-312, doi:10.1029/97GL03764, 1998.

Mishchenko, M. I., Cairns, B., Kopp, G., Schueler, C. F., Fafaul, B. A., Hansen, J. E., Hooker, R. J., Itchkawich, T., Maring, H. B., and Travis, L. D.: Accurate monitoring of terrestrial aerosols and total solar irradiance: introducing the glory mission, Bull. Am. Meteor. Soc., 88, 677, doi:10.1175/BAMS-88-5-677, 2007.

Mitchell, D., Liu, Y., and Macke, A.: Modeling cirrus clouds, Pt. II: Treatment of radiative properties, J. Atmos. Sci., 53, 2967-2988, 1996.

Nakajima, T. and King, M. D.: Determination of the optical thickness and effective particle radius of clouds from reflected solar radiation measurements, Pt. I: Theory, J. Atmos. Sci., 47, 1878-1893, doi:10.1175/15200469(1990)047<1878:DOTOTA > 2.0.CO;2, 1990.

Nelson, J.: Sublimation of Ice Crystals., J. Atmos. Sci., 55, 910919, doi:10.1175/1520-0469(1998)055<0910:SOIC > 2.0.CO;2, 1998.

Noel, V., Winker, D., McGill, M., and Lawson, P.: Classification of particle shapes from lidar depolarization ratios in convective ice clouds compared to in situ observations during CRYSTAL-FACE, J. Geophys. Res., 109, D24213, doi:10.1029/2004JD004883, 2004.

Noel, V., Winker, D. M., Garrett, T. J., and McGill, M.: Extinction coefficients retrieved in deep tropical ice clouds from lidar observations using a CALIPSO-like algorithm compared to in-situ measurements from the cloud integrating nephelometer during CRYSTAL-FACE, Atmos. Chem. Phys., 7, 1415-1422, doi:10.5194/acp-7-1415-2007, 2007.

Ott, L. E., Pickering, K. E., Stenchikov, G. L., Allen, D. J., DeCaria, A. J., Ridley, B., Lin, R.-F., Lang, S., and Tao, W.-K.: Production of lightning $\mathrm{NO}_{\mathrm{x}}$ and its vertical distribution calculated from three-dimensional cloud-scale chemical transport model simulations, J. Geophys. Res., 115, D04301, doi:10.1029/2009JD011880, 2010.

Ottaviani, M., Cairns, B., Chowdhary, J., van Diedenhoven, B., Knobelspiesse, K., Hostetler, C., Ferrare, R., Burton, S., Hair, J., Obland, M., and Rogers, R.: Polarimetric retrievals of surface and cirrus clouds properties in the region affected by the Deepwater Horizon oil spill, Remote Sens. Environ., 121, 389-403, doi:10.1016/j.rse.2012.02.016, 2012.

Platnick, S.: Vertical photon transport in cloud remote sensing problems, J. Geophys. Res., 105, 22919-22935, doi:10.1029/2000JD900333, 2000.

Platt, C. M. R., Reynolds, D. W., and Abshire, N. L.: Satellite and Lidar observations of the albedo, emittance and optical depth of cirrus compared to model calculations, Mon. Weather Rev., 108, 195-204, doi:10.1175/15200493(1980)108<0195:SALOOT>2.0.CO;2, 1980.

Sassen, K., Zhu, J., and Benson, S.: Midlatitude cirrus cloud climatology from the facility for atmospheric remote sensing, Pt. IV: Optical displays, Appl. Opt., 42, 332, doi:10.1364/AO.42.000332, 2003.

Sherwood, S. C.: Deep convective cloud-top heights and their thermodynamic control during CRYSTAL-FACE, J. Geophys. Res., 109, D20119, doi:10.1029/2004JD004811, 2004.

Sherwood, S. C., Phillips, V. T. J., and Wettlaufer, J. S.: Small ice crystals and the climatology of lightning, Geophys. Res. Lett., 33, L05804, doi:10.1029/2005GL025242, 2006.

Stephens, G. L., Tsay, S.-C., Stackhouse, P. W., J., and Flatau, P. J.: The relevance of the microphysical and radiative properties of cirrus clouds to climate and climatic feedback, J. Atmos. Sci., 47, 1742-1754, 1990.

Takano, Y. and Liou, K.-N.: Solar Radiative Transfer in Cirrus Clouds. Part I: Single-Scattering and Optical Properties of Hexagonal Ice Crystals, J. Atmos. Sci., 46, 3-19, doi:10.1175/1520-0469(1989)046<0003:SRTICC > 2.0.CO;2, 1989.

Ulanowski, Z., Hesse, E., Kaye, P., and Baran, A.: Light scattering by complex ice-analogue crystals, J. Quant. Spectrosc. Radiat. Transfer, 100, 382-392, doi:10.1016/j.jqsrt.2005.11.052, 2006.

Um, J. and McFarquhar, G. M.: Single-scattering properties of aggregates of bullet rosettes in cirrus, J. Appl. Meteor. Clim., 46, 757-775, doi:10.1175/JAM2501.1, 2007.

Um, J. and McFarquhar, G. M.: Single-scattering properties of aggregates of plates, Q. J. R. Meteorol. Soc, 135, 291-304, doi:10.1002/qj.378, 2009.

van de Hulst, H. C.: Light scattering by small particles, Dover Publications, New York, 1957.

van Diedenhoven, B., Cairns, B., Geogdzhayev, I. V., Fridlind, A. M., Ackerman, A. S., Yang, P., and Baum, B. A.: Remote sensing of ice crystal asymmetry parameter using multidirectional polarization measurements - Part 1: Methodology and evaluation with simulated measurements, Atmos. Meas. Tech., 5, 2361-2374, doi:10.5194/amt-5-2361-2012, 2012. 
van Diedenhoven, B., Fridlind, A. M., Ackerman, A. S., and Cairns, B.: Evaluation of hydrometeor phase and ice properties in cloudresolving model simulations of tropical deep convection using radiance and polarization measurements, J. Atmos. Sci., 69, 32903314, doi:10.1175/JAS-D-11-0314.1, 2012b.

Vogelmann, A. M. and Ackerman, T. P.: Relating cirrus cloud properties to observed fluxes: a critical assessment, J. Atmos. Sci., 52, 4285-4301, doi:10.1175/15200469(1995)052<4285:RCCPTO > 2.0.CO;2, 1995.

Yang, P., Kattawar, G., Hong, G., Minnis, P., and Hu, Y.: Uncertainties associated with the surface texture of ice particles in satellitebased retrieval of cirrus clouds - Part I: Single-scattering properties of ice crystals with surface roughness, IEEE Trans. Geosci. Rem. Sens., 46, 1940-1947, doi:10.1109/TGRS.2008.916471, 2008.
Yang, P. and Fu, Q.: Dependence of ice crystal optical properties on particle aspect ratio, J. Quant. Spectrosc. Rad. Transf., 110, 1604-1614, doi:10.1016/j.jqsrt.2009.03.004, 2009.

Yang, P., Bi, L., Baum, B. A., Liou, K.-N., Kattawar, G. W., Mishchenko, M. I., and Cole, B.: Spectrally consistent scattering, absorption, and polarization properties of atmospheric ice crystals at wavelengths from $0.2 \mu \mathrm{m}$ to $100 \mu \mathrm{m}$, J. Atmos. Sci., 70, 330-347, doi:10.1175/JAS-D-12-039.1, 2013.

Zhang, Z., Yang, P., Kattawar, G., Riedi, J., Labonnote, L. C., Baum, B. A., Platnick, S., and Huang, H.-L.: Influence of ice particle model on satellite ice cloud retrieval: lessons learned from MODIS and POLDER cloud product comparison, Atmos. Chem. Phys., 9, 7115-7129, doi:10.5194/acp-9-7115-2009, 2009.

Zhang, Z., Platnick, S., Yang, P., Heidinger, A. K., and Comstock, J. M.: Effects of ice particle size vertical inhomogeneity on the passive remote sensing of ice clouds, J. Geophys. Res., 115, D17203, doi:10.1029/2010JD013835, 2010. 